\title{
LAS BIBLIOTECAS ESCOLARES EN LA PRIMERA DÉCADA DEL FRANQUISMO: ENTRE EL AMANECER Y LA LUZ CEGADA
}

DOI: http://dx.doi.org/10.1590/2236-3459/66494

\author{
Xosé Manuel Malheiro Gutiérrez \\ Universidade da Coruña (UDC), España
}

$\cos 8$

\begin{abstract}
Resumen
Durante la guerra civil y primeros años de la dictadura del general Franco, el régimen surgido del golpe de estado se ocupó de barrer de la sociedad española toda huella republicana, especialmente en el campo pedagógico. Este texto reconstruye el proceso de expurgo de la biblioteca popular donada por el Patronato de Misiones Pedagógicas en el año 1935 a la escuela nacional de un pequeño pueblo de la provincia de Pontevedra. Se revisa la documentación del expediente que se conserva en el archivo de la escuela, compuesto por la correspondencia del maestro y los escritos oficiales, y se complementa con la necesaria revisión bibliográfica y de prensa periódica de la época. Ello nos permite documentar el proceso de depuración que se llevó a cabo en las bibliotecas públicas, como ejemplo del perpetrado en todo el Estado por parte de los golpistas; observar algunos rasgos de la orientación de la nueva política educativa y analizar el papel que se vieron obligados a desempeñar, a partir de ese momento, muchos maestros y maestras en un violento escenario de ruptura social, persecución política y sustitución ideológica.

Palabras clave: II República, franquismo, misiones pedagógicas, bibliotecas populares.
\end{abstract}

\section{AS BIBLIOTECAS ESCOLARES NA PRIMEIRA DÉCADA DO FRANQUISMO: ENTRE O AMANHECER E A LUZ CEGADA}

\section{Resumo}

Durante a guerra civil e primeiros anos da ditadura do general Franco, o regime surgido do golpe de estado ocupou-se de varrer da sociedade espanhola toda impressão republicana, especialmente no campo pedagógico. Este texto reconstrói o processo de expurgo da biblioteca popular doada pelo Padroado das Missões Pedagógicas no ano 1935 à escola nacional de um pequeno povo da província de Pontevedra. Revisa-se a documentação do expediente que se conserva no arquivo da escola, composto pela correspondência do professor e os escritos oficiais, e se complementa com a necessária revisão bibliográfica e de imprensa periódica da época. Isso permite-nos documentar o processo de depuração que se levou a cabo nas bibliotecas públicas, como exemplo do que foi perpetrado em todo o Estado por parte dos golpistas; observar alguns traços da orientação da nova política educativa e analisar o papel que se viram obrigados a desempenhar, a partir desse momento, muitos professores e professoras num violento cenário de ruptura social, perseguição política e substituição ideológica.

Palavras-chave: II República, franquismo, missões pedagógicas, bibliotecas populares. 


\title{
SCHOOL LIBRARIES IN THE FIRST DECADE OF THE FRANCO REGIME: BETWEEN DAWN AND THE BLIND LIGHT
}

\begin{abstract}
During the Civil War and the first years of the dictatorship of General Franco, the regime that emerged from the coup d'état swept away any Republican trace from the Spanish society, especially in the pedagogical field. This text restores the expurgated version from the popular library donated by the Board of Pedagogical Missions in 1935 to the national school of a small town in the province of Pontevedra. The file documentation that is kept in the school's file, composed of the teacher's correspondence and the official writings, is revised and completed with the necessary bibliography and press of that time period. This allows us to document the filtering process that took place in the public libraries, such as the perpetrated in the entire Nation by the participants of the coup d'état; to observe some features of the orientation of the role that teachers were forced to execute, from that moment on, in a violent scenario of social rupture, political persecution and ideological substitution.

Keywords: the IInd Republic, Franco's regime, pedagogic missions, popular libraries.
\end{abstract}

\section{LES BIBLIOTHÈQUES SCOLAIRES DANS LA PREMIÈRE DÉCENNIE DU RÉGIME DE FRANCO: ENTRE L'AUBE ET LA LUMIÉRE AVEUGLE}

\section{Résumé}

Pendant la période de la guerre civile espagnole et les premières années de la dictadure du général Franco, le régime établi après le coup d'État a eliminé de la sociéte espagnole tous les traces républicains, notamment dans la sphère pédagogique. Ce texte reconstruit le développement de débogage de la bibliothèque populaire donnée à l' école nationale d'un petit village de Pontevedra en 1935 par le Patronage des Missions Pédagogiques. On révise la documentation du dossier gardé dans l'archive de l'école, qui contient la correspondance du professeur et quelques écrits officiels, et puis nous avons fait une revisión de la bibliographie et la présse périodique à ce moment-là qui compléte notre travail. Ça nous a permis documenter la sort de débogage dans les bibliothèques publiques comme un example de celui qui a eu lieu dans tout I' État par les militaires putschistes; aussi, nous avons remarqué quelques caracteristiques de l'orientation de la nouvelle politique educative et analysé le rôle que beaucoup d'enseignants ont été obligés à jouer dans un violent environnement plein de rupture sociale, persécution politique et remplacement idéologique.

Mots-clés: deuxième République, franquisme, missions pédagogiques, bibliothèques populares. 


\section{Las Misiones Pedagógicas y la democratización de la cultura}

D as Misiones Pedagógicas nacieron en 1931 en el marco jurídico del Patronato que lleva su nombre como una novedosa iniciativa del primer gobierno republicano ${ }^{1}$ para extender el valor institucionista de acceso a la educación. Un programa más extenso, que tenía como meta urgente escolarizar a más de medio millón de niños y niñas, principalmente del medio rural, y la erradicación del analfabetismo en la población adulta, que al inicio de la década de los treinta padecía unas tasas del $37 \%$ para los hombres y de casi el $48 \%$ para las mujeres (LÓPEZ COBO, 2007 , p. 1). Además, la mayor parte de la población alfabetizada era ajena a la cultura escrita, y sólo cuatro millones, de los veintitrés que formaban la población española en 1934, tenían acceso al libro o a la prensa periódica. (FAUS SEVILLA, 1990).

Manuel Bartolomé Cossío fue el director del Patronato desde su fundación. Para fomentar la cultura general se creó un Servicio de Bibliotecas en el que participaron María Moliner, Juan Vicens de la Calle o Antonio Machado².

Las Misiones Pedagógicas nacieron para tratar de "democratizar la cultura". Como quedaba recogido en el artículo 48 de la Constitución, era a la vez un deber del Estado y un derecho de los ciudadanos. En concreto, y como afirma, Ana Martínez Rus (2013), las Misiones fueron un instrumento fundamental de la República para democratizar el saber y socializar la lectura. En este sentido, Tuñón de Lara señala que la política cultural republicana fue concebida como un derecho sociopolítico propio del nuevo régimen democrático, donde confluyeron las necesidades intelectuales de la sociedad civil más abandonada y las decisiones políticas de los gobiernos progresistas. Una idea en la que también insiste Redondo Abal (2014, p. 22-23) cuando resalta los esfuerzos del primer gobierno republicano

en la difusión del libro por los más variados rincones del país, permitiendo a todos los ciudadanos el acceso a la lectura independientemente del lugar de residencia, para rematar con la obscena discriminación del mundo rural respecto del urbano.

\section{El Servicio de Bibliotecas}

Un eje fundamental de ese ambicioso proyecto de educación popular fue el programa de lo que, en un lenguaje actual, llamaríamos "animación a la lectura". Se llevó a cabo mediante la distribución de bibliotecas escolares, fijas o itinerantes en todas las misiones realizadas. Este programa arranca en agosto de 1931, cuando se aprueba el Decreto que establece en su primer artículo que en toda escuela primaria debería haber una biblioteca que fuese pública en cuanto a su acceso y bajo responsabilidad de su

\footnotetext{
${ }^{1}$ El Ministerio de Instrucción Pública y Bellas Artes, siendo su titular primero Marcelino Domingo Sanjuán y después Fernando de los Ríos, creará el Patronato de Misiones Pedagógicas (29 de mayo de 1931 y desarrollado el 7 de agosto de 1931) y la Junta de Intercambio y Adquisición de Libros para Bibliotecas Públicas (21 de noviembre de 1931 y desarrollado el 13 de junio de 1932). Patronato y Junta colaborarán en este proyecto repartiendo bibliotecas por todo el Estado.

${ }^{2}$ Además, también se crearon las siguientes secciones itinerantes: el Coro del Pueblo, dirigido por Eduardo Martínez Torner; el Teatro del Pueblo, organizado por Eduardo Marquina y más tarde por Alejandro Casona, al que había de sumarse el Retablo de Fantoches, que se incorpora a partir de una improvisación ejecutada por Rafael Dieste en la misión a Galicia; el Museo Circulante, explicado por Antonio Sánchez Barbudo, Ramón Gaya y Luis Cernuda entre otros; la Sección de Cine y Proyecciones Fijas, que contó con un cinematógrafo manejado por José Val del Omar; y un Servicio de Música, cuya selección corría a cargo del compositor Óscar Esplá, que distribuía gramófonos y discos de pizarra.
} 
maestro. Este sería el encargado de organizar el catálogo, de controlar el registro de ingresos y gastos y de gestionar el servicio de préstamo. Porque dicha biblioteca debía facilitar servicio de lectura en sala o en préstamo gratuito, ubicada en una espacio diferenciado del aula. Su administración correspondería al Consejo local de Primera Enseñanza, encargado además de redactar un Reglamento. Éste podría organizar fiestas y colectas para poder afrontar nuevas adquisiciones; celebraría lecturas públicas y conferencias sobre sus fondos; negociaría con las bibliotecas vecinas el intercambio de libros; aprobaría el presupuesto y propondría al inspector de Primera Enseñanza las obras a adquirir.

Nos recuerda Martínez Rus (2003, p. 26) que antes de la intervención del Patronato con su Servicio de Bibliotecas, apenas existían librerías, salvo en las poblaciones de cierta importancia. Las bibliotecas públicas se localizaban en las capitales de provincia, y a ellas tenían acceso únicamente sus habitantes y especialmente los alumnos de enseñanza secundaria y universitaria.

Con la llegada de la Segunda República, el concepto y función de la biblioteca también se transformó. La instalación de nuevas bibliotecas y la actualización de las colecciones existentes tuvo un efecto multiplicador al aumentar la consulta de los lectores habituales, y aficionar a los libros a personas secularmente alejadas de lo impreso. Teniendo en cuenta estos factores, el Servicio de Bibliotecas de las Misiones Pedagógicas dio preferencia a las escuelas nacionales del medio rural y a las provincias más desfavorecidas.

Para conseguir que todas las escuelas tuvieran una biblioteca, se elaboró un plan de desarrollo de la política bibliotecaria, y se encargó al Patronado y a la Junta de Intercambio y Adquisición de Libros para Bibliotecas Públicas su distribución e implantación, a través de una coordinación establecida desde el Museo Pedagógico Nacional. El Patronato fue el responsable de distribuir más de cinco mil bibliotecas, que a su vez contenían más de medio millón de libros (LÓPEZ COBO, 2007, p. 89). En este sentido, la biblioteca fue concebida como un instrumento de socialización, al difundir obras literarias y científicas, de diversas procedencias y géneros, como veremos en el ejemplo que ilustra este trabajo, para elevar su formación intelectual y profesional y facilitar el ejercicio de los nuevos derechos constitucionales.

De ese modo, el Patronato, a través de las Misiones, fue el encargado de promocionar el hábito lector entre adultos y escolares en los lugares alejados de los espacios urbanos, intensificando "la activa colaboración que viene prestando para el mejoramiento de la Escuela primaria y la supresión del analfabetismo"3. El Patronado, se explica en el folleto, "aspira a que sus bibliotecas sean un elemento vivo". Las autoridades educativas, mayoritariamente procedentes de las aulas institucionistas tanto como de sus influencias, consideraron que había llegado el momento de alfabetizar a la población y asegurar su acceso al libro con el fin de mejorar su formación cultural y cívica al objeto de formar ciudadanos para la libre participación en la vida pública.

Al catálogo de las bibliotecas que repartió el Patronato habrían de sumarse las donaciones de los municipios, de las diputaciones o de particulares, con el objetivo de crear en cada escuela rural un lugar de reunión vecinal, y un germen de actividad cultural

3 PATRONATO DE MISIONES PEDAGÓGICAS. Reglas para la concesión y funcionamiento de las bibliotecas. Madrid: S. Aguirre Impresor, s/a. (Folleto sin fecha y sin paginar). 
que propiciara la difusión de libros y la normalización del hábito lector. Entre 1932 y 1933 se registraron 467.775 lectores (el 57 '5\% niños) y 2.196 .495 lecturas (el $64 \%$ infantiles). La Memoria editada por el Patronato señala que, según informaciones recogidas, "son los muchachos, de ordinario, quienes mueven a leer a sus padres y hermanos. Libro que el chico lleva a su casa es leído por el resto de la familia". (PATRONATO, 1934, p. 64).

Junto a éstas deben citarse las bibliotecas de carácter municipal que entregaba en los ayuntamientos la Junta de Intercambio. Establecimientos de mayor envergadura, situadas en localidades mayores, pero igualmente abiertas al conjunto de la población ${ }^{4}$.

\section{El fondo bibliográfico}

Aunque no fue el mismo para todas las escuelas, el fondo bibliográfico estaba formado, en su conjunto, por

obras de la literatura universal y española, clásica y moderna; arte, ciencias aplicadas, historia, geografía, técnicas agrícola e industrial, educación, ciencias naturales, ensayos, sociología, lecturas infantiles, viajes, biografías, diccionarios, etc. (PATRONATO, 1934, p. 64).

Las lecturas se clasificaron en dos grandes grupos: uno destinado a la infancia en el entorno escolar como complemento a las actividades académicas, y otro a los adultos, ampliando el concepto de biblioteca como un servicio público accesible a toda la ciudadanía.

El primer grupo se nutría de una colección de lecturas formativas infantiles que "representan la vida orientada al futuro, a las amplias creaciones que permiten a la imaginación infantil relacionar con el mundo visible otro mundo ensoñado" (PATRONATO, 1934, p. 67). El grupo de los adultos, en cambio, estaba formado mayoritariamente por novela, poesía y algunas obras de carácter práctico, relacionadas con agricultura 0 ganadería, además de otras que figuraban entre los libros solicitados en determinadas bibliotecas. Junto con los libros se enviaba papel para forrarlos, marcadores y talonarios para llevar un control estadístico de los lectores y de sus lecturas, de las que posteriormente se informaba al Patronato.

En cuanto a las preferencias, se señala para los lectores infantiles a los clásicos Perrault, Grimm, Andersen, Hoffman, Las mil y una noches, y las ediciones extractadas de Homero y Dante. También las novelas de aventuras de Switf, Verne, Lagerlof, Kipling, y los libros de biografías. Entre los adultos destacan los textos de Cervantes, Quevedo, Dickens, Tolstoi, Hugo, Remarque, La Breve historia del mundo de Wells, Galdós, Valera o Pérez de Ayala. En poesía, Bécquer, Antonio Machado y la prosa poética de Platero y

\footnotetext{
4 La Junta de Intercambio se ocupó, además, del movimiento bibliotecario privado con la entrega de numerosos lotes de libros a centros políticos, profesionales, sindicales o deportivos con carácter cultural, consciente de las deficiencias del sistema de bibliotecas públicas. Dicha Junta tuvo, entre otras, la función de modernizar el patrimonio bibliográfico nacional, dotar y expandir las bibliotecas públicas del Estado, donar lotes de libros a centros o sociedades particulares de carácter cultural y formar y distribuir partidas de libros para que las bibliotecas públicas contaran con sección circulante, en colaboración con las Misiones. María Moliner fue la encargada de diseñar el Proyecto de Bases de un Plan de Organización General de Bibliotecas del Estado, que no llegó a ver la luz a causa del golpe de estado de 1936. Como es bien sabido, la represión durante la guerra civil y el cambio de régimen se llevaron por delante todas las iniciativas republicanas a favor de la extensión popular de la cultura letrada y de los llamados registros cultos. Martínez Rus, A. (2013).
} 
yo. También se señala la gran acogida que en determinadas zonas se concede a las obras técnicas o de divulgación científica. (PATRONATO, 1934, p. 68).

De este modo afirmaba Cossío, las bibliotecas que se fueron repartiendo por las escuelitas rurales del Estado de las que había hablado Luís Bello, ayudaban a reducir el desconocimiento e incluso la indiferencia de la gente hacia los libros, pues el problema no consistía únicamente en que los campesinos consiguieran descifrar los signos escritos, sino en despertar el amor a la lectura. El promotor de este proyecto de intervención social quería lograr que incluso en las aldeas más lejanas los textos de lectura de la población dejaran de ser, exclusivamente, los catecismos y los calendarios, como venía siendo frecuente en la escuela pública decimonónica, y que a través de la biblioteca escolar, variada y útil, el libro llegara a todos los hogares, en préstamo, a través de hábito lector del alumnado (PATRONATO, 1934, p. 67):

Son los muchachos, de ordinario, según los datos recibidos, quienes mueven a leer a sus padres y hermanos. Libro que el chico lleva a casa es leído por el resto de la familia. En otros pueblos la biblioteca ha servido para estimular al vecindario para formar pequeñas sociedades de lecturas que allegan recursos destinados a la adquisición de nuevas obras.

La selección de los libros, competencia del Patronato, fue muy vigilada por parte de las organizaciones políticas conservadoras. Por eso, a ojos de muchos sectores políticos y sociales de los años treinta, la actividad del Patronato resultaba perniciosa, cuando no ya subversiva o incluso "revolucionaria", aspecto en el que nos detendremos más adelante. En este marco de difusión popular de valores laicos, democráticos y republicanos, el Patronato de Misiones Pedagógicas realizó un interesante programa por diversas provincias españolas ${ }^{5}$.

\section{La Biblioteca de las Misiones Pedagógicas en la escuela nacional de niños y niñas de Estás (Tomiño)}

La Biblioteca de la escuela de Estás, una pequeña población rural orillada al río Miño, relativamente cerca de su desembocadura limítrofe con Portugal, fue solicitada al Presidente del Patronato por la corporación municipal a través de la Inspección de Enseñanza Primaria. Como todas las que se promovieron desde el Patronato, estaba formada por un lote de cien volúmenes.

El 14 de diciembre de 1934, la secretaria administrativa, además de misionera, Matilde Moliner, gira escrito a Domingo Garcés Campo ${ }^{6}$, maestro nacional en la escuela de niños de Estás, para informarle de la concesión de una biblioteca, rogándole elaborase

\footnotetext{
5 Programa que llegó también a Galicia. Desde Ribadeo (Lugo) a A Guarda (Pontevedra) y desde Xinzo de Limia (Ourense) a Malpica (A Coruña) se desarrollaron una serie de actividades que Otero Urtaza y Porto Ucha han examinado de forma muy detallada en sus respectivos trabajos. Del primero debe citarse: (1982), (1991), (2006a), (2006b), (2006c) y (2007); del segundo: (2005).

6 En la época en que el Patronato de Misiones Pedagógicas enviaba la biblioteca itinerante a las escuelas de niños y niñas de Estás, estas se trasladaban a un nuevo edificio que se había construido por medio da "Fundación Peirópolis", una institución benéfico docente fundada por Abdón Alonso Alonso [Estás, 1874Peirópolis (Brasil), 1960], un emigrante de aquella parroquia, próspero empresario afincado en esa ciudad brasileña y que dedicó una parte importante de su fortuna a sostener diversas obras filantrópicas ligadas a la educación a la beneficencia en Peirópolis, su residencia en América, y en su ayuntamiento natal, entre las que figura esta escuela de enseñanza primaria.
} 
una relación de las obras enviadas y se la remitiese firmada y con acuse de recibo. Junto con los libros se envían también hojas para forrarlos, indicaciones para su cuidado y conservación, talonarios de préstamos y marcadores "para señalar la página donde se suspende la lectura"7.

El lote estaba dividido en dos secciones. Una colección de piezas clásicas de literatura universal orientada a la lectura infantil (Walter Scott, Quintín Duwart; Lewis Carrol, Alicia en el País de las Maravillas; Robert L. Stevenson, La Isla del Tesoro; Charles Dickens, Grandes llusiones; Julio Verne, Cinco semanas en globo; Ernst T. Amadeus Hoffmann, El tonelero de Nuremberg); además de una colección representativa de poesía, teatro o narrativa española. También se incluyen algunas piezas de pedagogía para orientación de los maestros y maestras (Estudios sobre educación de Francisco Giner, Cómo enseña Gertrudis a sus hijos de Pestalozzi, Las Escuelas Nuevas italianas de Concepción S. Amor, Las Escuelas Nuevas norteamericanas de Fernando Sáinz), de viajes y meditaciones (Notas de andar y ver, de Ortega y Gasset) o de pensamiento político (El origen de la familia, de F. Engels; Cómo se forja un pueblo, de Rodolfo Llopis o Ideario de Costa, de José García Mercadal). Como complemento, se envía el Diccionario Enciclopédico Ilustrado de la Lengua Española de la editorial Ramón Sopena, un Atlas Universal de la editorial Edelvives y algunas obras de geografía de Joan Palau Vera y Diego Pastor, e historia de España (Episodios nacionales, Benito Pérez Galdós o Historia de la civilización española, Rafael Altamira), otras de iniciación a la naturaleza (Curiosos pobladores del mar, Enrique Rioja Lo Bianco; Los meteoros, E. Sema) y algunas otras obras complementarias a las enseñanzas curriculares (La fotografía y el cinematógrafo, Vicente Vera; Nuestro organismo, Juan Vázquez; La navegación, A Cabrera; Historia de la arquitectura cristiana, Vicente Lampérez y Romea).

La sección destinada al público general se nutría de una selección de autores de la literatura española y universal. Se observa un carácter transversal, desde un punto de vista cronológico o incluso por la diversidad de géneros y temas. Desde la Edad Media (el infante Don Juan Manuel, El Conde Lucanor) El Siglo de Oro (Cervantes, El Quijote; Lope de Vega, Peribáñez y el Comendador de Ocaña; Francisco Quevedo, Los Sueños; Calderón de la Barca, Teatro; Fernando de Rojas, La Celestina; Agustín Moreto, Comedias), el Romanticismo (Mariano José de Larra, Artículos de costumbres; Gustavo Adolfo Bécquer, Obras escogidas; José de Espronceda, Poesías; Duque de Rivas, El Moro Expósito), o los siglos XIX y XX (Juan Valera, Pepita Giménez; Emilia Pardo Bazán, Cuentos de Marineda; José María de Pereda, El sabor de la Tierruca; Pío Baroja, La ciudad de la Niebla; Vicente Blasco Ibáñez, Cuentos valencianos; Juan R. Jiménez, Platero y yo; Valle Inclán, Sonata de estío).

Entre la literatura internacional, encontramos figuras claves para una panorámica general del pensamiento, donde predominan los autores occidentales con la excepción de Rabindranath Tagore (La luna nueva. Poemas de niños). Desde los clásicos Homero (Ilíada) o Lucio Apuleyo (El asno de oro), hasta la edad contemporánea. Así, la literatura rusa de la segunda mitad del siglo XIX quedó representada con la elección de las obras de Leónidas Andreiev (Sachka Yegulev), Feodor Mijailovich Dostoievski (Crimen y Castigo) o León Tolstoi (Mis memorias). Amplia presencia tuvo también la literatura

7 Carta remitida por María Moliner a Domingo Garcés desde el patronato, con fecha 14 de diciembre de 1934. Documento suelto sin paginar. 
francesa con escritores como Gustavo Flaubert (La educación sentimental), Honoré de Balzac (Papá Goriot), Victor Hugo (Los trabajadores del mar), Henri Beyle Stendhal (La Cartuja de Parma), Julio Verne ya mencionado, o Molière (El enfermo de aprensión). Los clásicos británicos estaban representados por los ya mencionados Defoe, Dickens, Scott o Stevenson. Los autores alemanes elegidos fueron Friedrich Schiller (Obras dramáticas) o el citado Friedrich Engels. Con menos presencia, pero con obras fundamentales, se incluye la literatura portuguesa con Luiz de Camoens (Los Lusíadas), la norteamericana con Washington Irving (Cuentos de la Alambra) o la italiana con Benvenuto Cellini (Mi vida). Además, aparecen algunos libros más orientados al contexto rural donde se enviaba la biblioteca, como la Guía del Horticultor, La huerta y el corral de Juan Nonell, Cómo se elige un arado de José Cruz Lapazarán o Abejas y colmenas de De la Escalera y Suja.

Un centenar de obras que componían un significativo catálogo, atendiendo al informe remitido por el maestro Domingo Garcés al Secretario del Patronato con fecha 31 de enero de 1936 (Cuadro 01). En el mismo, Garcés indicaba la ausencia del segundo tomo de la obra del intelectual krausista Ramón Pérez de Ayala Tigre Juan; el curandero de su Honra, para completar la centena de obras del catálogo. Al mismo tiempo, solicitaba el envío de más obras de carácter agrícola y de novelas.

Cuadro 01 - Relación de obras que el Patronato de Misiones Pedagógicas envió a la escuela de Estás (Tomiño) en 1935.

\begin{tabular}{|c|c|c|c|c|c|}
\hline & Título & Autor & & Título & Autor \\
\hline 1 & Atlas Universal & Edelvides & 51 & La navegación & A. Cabrera \\
\hline 2 & $\begin{array}{l}\text { Diccionario } \\
\text { Enciclopédico } \\
\text { llustrado }\end{array}$ & La Fuente & 52 & Pepita Giménez & Juan Valera \\
\hline 3 & Júbilos & Carmen Conde & 53 & Tigre Juan & $\begin{array}{l}\text { Ramón Pérez de } \\
\text { Ayala }\end{array}$ \\
\hline 4 & Quintín Duwart & Walter Scott & 54 & $\begin{array}{l}\text { Curiosos pobladores } \\
\text { del mar }\end{array}$ & Enrique Rioja \\
\hline 5 & $\begin{array}{l}\text { Los trabajadores del } \\
\text { mar }\end{array}$ & Víctor Hugo & 55 & $\begin{array}{l}\text { Alicia en el País de las } \\
\text { Maravillas }\end{array}$ & Lewis Carrol \\
\hline 6 & $\begin{array}{l}\text { La luna nueva: } \\
\text { poemas de niños }\end{array}$ & Rabindranat Tagore & 56 & $\begin{array}{l}\text { Cuentos de los } \\
\text { Juguetes Vivos }\end{array}$ & Antonio Robles \\
\hline 7 & El almacén de cuentos & Saturnino Calleja & 57 & La Isla del Tesoro & $\begin{array}{l}\text { Robert Louis } \\
\text { Stevenson }\end{array}$ \\
\hline 8 & $\begin{array}{l}\text { Sucesos } \\
\text { extraordinarios }\end{array}$ & Saturnino Calleja & 58 & Grandes Ilusiones & Charles Dickens* \\
\hline 9 & $\begin{array}{l}\text { El ingenioso hidalgo D. } \\
\text { Quijote de la Mancha }\end{array}$ & Miguel de Cervantes & 59 & $\begin{array}{l}\text { Cinco semanas en } \\
\text { globo }\end{array}$ & Julio Verne \\
\hline 10 & $\begin{array}{l}\text { Estudios sobre } \\
\text { educación }\end{array}$ & Francisco Giner & 60 & $\begin{array}{l}\text { Vida y desventuras de } \\
\text { M. de Cervantes }\end{array}$ & Mariano Tomás \\
\hline 11 & Obras escogidas & Gustavo A. Bécquer & 61 & $\begin{array}{l}\text { Cómo se elige un } \\
\text { arado }\end{array}$ & José Cruz Lapazarán \\
\hline 12 & El sabor de la Tierruca & José María de Pereda & 62 & Abejas y Colmenas & $\begin{array}{l}\text { F. M. de la Escalera, } \\
\text { Ernesto Suja }\end{array}$ \\
\hline
\end{tabular}




\begin{tabular}{|c|c|c|c|c|c|}
\hline & Título & Autor & & Título & Autor \\
\hline 13 & Obras dramáticas & Friedrich Schiller & 63 & Los meteoros & E. Sema \\
\hline 14 & Poesías completas & Antonio Machado & 64 & $\begin{array}{l}\text { Las Escuelas Nuevas } \\
\text { italianas }\end{array}$ & Concepción S. Amor \\
\hline 15 & Mi vida & Benvenuto Cellini & 65 & $\begin{array}{l}\text { Las Escuelas Nuevas } \\
\text { norteamericanas }\end{array}$ & Fernando Sáinz \\
\hline 16 & Platero y yo & Juan Ramón Jiménez & 66 & $\begin{array}{l}\text { Viaje sentimental de } \\
\text { un inglés a Francia }\end{array}$ & Laurence Sterne \\
\hline 17 & Cuentos de Marineda & Emilia Pardo Bazán & 67 & $\begin{array}{l}\text { El tonelero de } \\
\text { Nuremberg }\end{array}$ & Ernst T. A. Hoffmann \\
\hline 18 & Ilíada (Tomo 1) & Homero & 68 & El origen de la familia & Friedrich Engels \\
\hline 19 & llíada (Tomo 2) & Homero & 69 & Comedias & Agustín Moreto \\
\hline 20 & $\begin{array}{l}\text { Cómo enseña } \\
\text { Gertrudis a sus hijos }\end{array}$ & Johann H. Pestalozzi & 70 & Teatro & $\begin{array}{l}\text { P. Calderón de la } \\
\text { Barca }\end{array}$ \\
\hline 21 & $\begin{array}{l}\text { La campaña del } \\
\text { maestrazgo }\end{array}$ & Benito Pérez Galdós & 71 & El Conde Lucanor & Don Juan Manuel \\
\hline 22 & Cádiz & Benito Pérez Galdós & 72 & Obras Completas & William Shakespeare \\
\hline 23 & Sonata de estío & $\begin{array}{l}\text { Ramón del Valle } \\
\text { Inclán }\end{array}$ & 73 & La Celestina & Fernando de Rojas \\
\hline 24 & Trafalgar & Benito Pérez Galdós & 74 & $\begin{array}{l}\text { La Cartuja de Parma } \\
\text { (Tomo 1) }\end{array}$ & Henri Beyle Stendhal \\
\hline 25 & La ciudad de la niebla & Pío Baroja & 75 & $\begin{array}{l}\text { La Cartuja de Parma } \\
\text { (Tomo 2) }\end{array}$ & Henri Beyle Stendhal \\
\hline 26 & Cuentos Valencianos & Vicente Blasco Ibáñez & 76 & Papá Goriot & Honoré de Balzac \\
\hline 27 & $\begin{array}{l}\text { Crimen y castigo } \\
\text { (Tomo 1) }\end{array}$ & Fiódor Dostoieswki & 77 & Notas & José Ortega y Gasset \\
\hline 28 & $\begin{array}{l}\text { Crimen y castigo } \\
\text { (Tomo 2) }\end{array}$ & Fiódor Dostoieswki & 78 & El Asno de Oro & Lucio Apuleyo \\
\hline 29 & Mis memorias & Leon Tolstoy & 79 & $\begin{array}{l}\text { Cien romances } \\
\text { escogidos }\end{array}$ & $\begin{array}{l}\text { Antonio García } \\
\text { Solalinde }\end{array}$ \\
\hline 30 & Ideario de Costa & José García Mercadal & 80 & Sachka Yegulev & Leónidas Andreiev \\
\hline 31 & $\begin{array}{l}\text { Cómo se forja un } \\
\text { pueblo }\end{array}$ & Rodolfo Llopis & 81 & El lazarillo de Tormes & Anónimo \\
\hline 32 & $\begin{array}{l}\text { Lecturas geográficas I. } \\
\text { Asia y África }\end{array}$ & Diego Pastor & 82 & 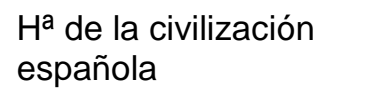 & Rafael Altamira \\
\hline 33 & $\begin{array}{l}\text { Lecturas geográficas } \\
\text { II. América y Oceanía }\end{array}$ & Diego Pastor & 83 & $\begin{array}{l}\text { El enfermo de } \\
\text { aprensión }\end{array}$ & $\begin{array}{l}\text { Jean-Baptiste } \\
\text { Poquelin, Moliére }\end{array}$ \\
\hline 34 & $\begin{array}{l}\text { Lecturas geográficas } \\
\text { III. Europa }\end{array}$ & Diego Pastor & 84 & $\begin{array}{l}\mathrm{H}^{\mathrm{a}} \text { de la arquitectura } \\
\text { cristiana }\end{array}$ & $\begin{array}{l}\text { Vicente Lampérez y } \\
\text { Romea }\end{array}$ \\
\hline 35 & $\begin{array}{l}\text { Lecturas geográficas } \\
\text { IV. España y Portugal }\end{array}$ & Diego Pastor & 85 & $\begin{array}{l}\text { Historias de Hans } \\
\text { Andersen }\end{array}$ & Mary McGregor \\
\hline 36 & Geografía Humana & Joan Palau Vera & 86 & Los Héroes & Mary McGregor \\
\hline 37 & $\begin{array}{l}\text { Vida de Alejandro } \\
\text { Magno }\end{array}$ & Joan Palau Vera & 87 & Los Lusíadas & Luiz de Camoens \\
\hline 38 & $\begin{array}{l}\text { Vida de Cristóbal } \\
\text { Colón }\end{array}$ & Joan Palau Vera & 88 & $\begin{array}{l}\text { Cuentos de la } \\
\text { Alhambra }\end{array}$ & Washington Irving \\
\hline
\end{tabular}




\begin{tabular}{|c|c|c|c|c|c|}
\hline & Título & Autor & & Título & Autor \\
\hline 39 & $\begin{array}{l}\text { Vida de George } \\
\text { Stephenson }\end{array}$ & Joan Palau Vera & 89 & $\begin{array}{l}\text { La educación } \\
\text { sentimental (T. 1) }\end{array}$ & Gustave Flauvert \\
\hline 40 & Vida de Julio César & Joan Palau Vera & 90 & $\begin{array}{l}\text { La educación } \\
\text { sentimental (T. 2) }\end{array}$ & Gustave Flauvert \\
\hline 41 & $\begin{array}{l}\text { Geografía de España } \\
\text { y Portugal }\end{array}$ & Joan Palau Vera & 91 & $\begin{array}{l}\text { Los sueños (Tomos } 1 \\
\text { e 2) }\end{array}$ & Francisco de Quevedo \\
\hline 42 & Nuestro organismo & Juan Vázquez & 92 & $\begin{array}{l}\text { Los sueños (Tomos } 1 \\
\text { e 2) }\end{array}$ & Francisco de Quevedo \\
\hline 43 & $\begin{array}{l}\text { Figuras de la Pasión } \\
\text { del Señor }\end{array}$ & Gabriel Miró & 93 & $\begin{array}{l}\text { Las cien mejores } \\
\text { poesías }\end{array}$ & $\begin{array}{l}\text { Selecc. de Menéndez } \\
\text { Pelayo }\end{array}$ \\
\hline 44 & Dulce nombre & Concha Espina & 94 & Poesías & José de Espronceda \\
\hline 45 & Flor de leyendas & Alejandro Casona & 95 & $\begin{array}{l}\text { Artículos de } \\
\text { costumbres (Tomo 1) }\end{array}$ & Mariano José de Larra \\
\hline 46 & Miguel Servet & A. Martínez & 96 & $\begin{array}{l}\text { Artículos de } \\
\text { costumbres (Tomo 2) }\end{array}$ & Mariano José de Larra \\
\hline 47 & $\begin{array}{l}\text { Guía del Horticultor. } \\
\text { La huerta y el corral }\end{array}$ & Juan Nonell & 97 & $\begin{array}{l}\text { El Moro Expósito } \\
\text { (Tomo 1) }\end{array}$ & Duque de Rivas \\
\hline 48 & $\begin{array}{l}\text { La fotografía y el } \\
\text { cinematógrafo }\end{array}$ & Vicente Vera & 98 & $\begin{array}{l}\text { El Moro Expósito } \\
\text { (Tomo 2) }\end{array}$ & Duque de Rivas \\
\hline 49 & $\begin{array}{l}\text { Poesía en prosa y } \\
\text { verso }\end{array}$ & Juan Ramón Jiménez & 99 & $\begin{array}{l}\text { Peribáñez y el } \\
\text { Comendador de } \\
\text { Ocaña }\end{array}$ & Lope de Vega \\
\hline 50 & La vida de los Astros & José Tinoco & & & \\
\hline
\end{tabular}

Fuente: elaboración propia a partir de la documentación contenida en el expediente que se conserva en el archivo de la escuela.

Constaba como fecha de alta del servicio de lectura el día 9 de enero de 1935, con un número total de 53 lectores registrados hasta ese momento, correspondiendo 36 a lectores escolares y 17 a lectores adultos. El número de lecturas registradas por los escolares ascendía a 128, y 52 la de los adultos. Entre los libros preferidos de los críos se encontraban Lecturas Geográficas de los cinco continentes, de Diego Pastor; Almacén de Cuentos y Sucesos extraordinarios, de Saturnino Calleja; una colección de retratos biográficos, Vidas, sobre Alejandro Magno, Cristóbal Colón, Julio César, George Stephenson... de Juan Palau Vera y La Isla del Tesoro, de Robert Louis Stevenson. Por su parte, entre las lecturas preferidas por los adultos destacaban El ingenioso hidalgo Don Quijote de la Mancha de Cervantes; Tigre Juan de Ramón Pérez de Ayala; Guía del horticultor para la siembra y aclimatación de las hortalizas, de Juan Nonell; Abejas y colmenas, de Fernando Martínez de la Escalera y Ernesto Suja; y Cómo se elige un arado, de José Cruz Lapazarán.

De este modo vivo y abierto pudieron transcurrir los días republicanos de esta Biblioteca escolar, la que pronto se iba a ver sometida a un expurgo como consecuencia de la censura y falta de libertad.

\section{El Patronato de Misiones Pedagógicas se transforma}

La transformación del Patronato de Misiones Pedagógicas en el Patronato de 
Cultura Popular se lleva a cabo por Orden ministerial de 19 de junio de 1939 y se encuadra en el marco del desmantelamiento de la política educativa republicana perpetrado por el nuevo régimen con la ayuda de la Iglesia católica ${ }^{8}$. Tiburcio Romualdo de Toledo y Robles, a la sazón Director General de Primera Enseñanza, acusaba en 1940 al anterior Patronato de ser "introductor en España de la escuela soviética, organismo de propaganda al servicio del marxismo internacional, cuya desaparición total no pudo conseguirse en Las Cortes del bienio cedolerrouxista". (DE TOLEDO, 1940, p. 215).

Al mismo tiempo que se pone en marcha la depuración de las instituciones, se lleva a cabo en la llamada "zona nacional" la purga de los cuerpos docentes; principalmente del magisterio primario que se había significado en el apoyo a la política republicana: "Los maestros peligrosos fueron substituidos o llamados a la cordura" (ALONSO MONTERO; VILLAR, 1999, p. 25). Como ya han destacado diferentes autores, muertos, depurados o exiliados un gran número de profesores, la plantilla docente de las universidades tuvo que ser renovada, entre 1939 y 1945, en más de la mitad de sus componentes y ocupada por el poder político del nuevo sistema ${ }^{9}$. Y si el Patronato acabó decapitado en 1939, dependiente del nuevo Ministerio de Educación Nacional, las Misiones Pedagógicas, y en particular la selección y reparto de los libros, que era de su competencia, ya habían sido insistentemente acosadas durante toda la etapa republicana por parte de las organizaciones políticas conservadoras, aunque con mayor intensidad durante el bienio 1933-35. Repartir libros y enseñar a leer era visto como una iniciativa preocupante, porque podía distraer a los campesinos de las ocupaciones a las que estaban 'naturalmente' destinados y, dicho sea de paso, para las que 'no necesitaban ninguna formación intelectual'. Además, la lectura de ciertos textos podría suscitar en ellos nuevas e inquietantes ideas sobre derechos y libertades, y la tentación de cuestionar el orden establecido. Por eso, a ojos de muchos sectores políticos y sociales de los años treinta, la actividad del Patronato resultaba perniciosa, cuando no ya subversiva o incluso revolucionaria y había que bloquearla.

Es así como el boicot a las bibliotecas ya se materializa, en alguna medida, a partir de 1933 formando parte de la paralización de todas las iniciativas de los anteriores consistorios. Y de este modo, los cambios políticos durante este período determinaron el desarrollo de las bibliotecas, debido a la mayor o menor implicación de las autoridades municipales en las juntas bibliotecarias. Mientras que en el año 1933 la consignación dedicada a Misiones había sido de 700.000 ptas. y de 100.000 ptas. la compra de libros,

8 Formó parte de esa poda ideológica el relevo de una serie de organismos singulares de la política educativa republicana por otros, estrechamente colaboradores del Nuevo Estado y afines a él. De este modo, una institución prestigiosa como la Junta de Ampliación de Estudios (JAE) fue sustituida por el nuevo Consejo Superior de Investigaciones Científicas (CSIC); el antiguo Instituto-Escuela fue reconvertido en el Instituto piloto "Ramiro de Maeztu", y el depurado Museo Pedagógico Nacional, en el Instituto de Pedagogía "San José de Calasanz". Se creó, además, la Universidad Pontificia de Salamanca con especial interés en la formación de futuros maestros. Y fuera de la educación reglada, pero con un fuerte componente formativo en el ámbito ideológico, nacen también el Frente de Juventudes y la Sección Femenina. En Galicia, por ejemplo, el Seminario de Estudos Galegos, institución que había nacido para promover la lengua y cultura gallegas, integrando a una buena parte de la intelectualidad galleguista fue transformado a partir de 1943 en el culturalmente arqueologizante Instituto de Estudios Gallegos Padre Sarmiento.

${ }^{9}$ Entre la infinidad de trabajos sobre la represión de los cuerpos docentes se recomienda, para el conjunto del Estado, la obra de Morente Valero (1997). Para el caso de Galicia, véanse los trabajos de los siguientes autores: Costa Rico (2004); Porto Ucha (2008); Cid Fernández (2010); Souto Blanco (1998) o Gurriarán (2006). 
en 1934 el presupuesto del Patronato de Misiones se vio reducido a 650.000 pesetas y a 50.000 la cantidad destinada a las bibliotecas (MARTÍNEZ RUS, 2013). Y en este sentido, entre otras anécdotas que pudiesen referirse está la que nos recuerda Rafael Valls (2007, p. 42): en 1935, el ministro de Instrucción Pública Joaquín Dualde, a petición de varios diputados de su grupo, el Partido Liberal Demócrata, ordenó la retirada del libro de Albert Thomas, Lecturas históricas: historia anecdótica del trabajo. Un manual para uso escolar en la línea de la cultura cívica republicana y cuyo autor había sido el primer presidente de la Organización Internacional del Trabajo además de un destacado socialista. Como también nos recuerda Carmen Diego Pérez, esta obra se utilizó como libro de lectura escolar oficial en Francia, Alemania, el Reino Unido y Holanda. En España fue traducida y adaptada por Rodolfo Llopis, Director General de Primera Enseñanza entre 1931 y 1933, que escribió para esta versión los capítulos 25, 29 y 31: "Los alpargateros de Elche", "Pablo Iglesias" y "El proletariado español"10. Y ahí había empezado ya el expurgo.

Ahora, se procedía sin dilación ni titubeos a una política de desbroce que los sublevados inician, de inmediato, en pleno período bélico en la zona ocupada. El Decreto no 108 de 13 de septiembre de $1936^{11}$ había declarado "fuera de la Ley" todos los partidos y agrupaciones políticas del Frente Popular, lo que desencadenó una salvaje "incautación de cuantos bienes muebles, inmuebles, efectos y documentos" fuesen propiedad de dichas organizaciones. Y dio lugar, además, a una intensa actividad depuradora que, entre otras instancias de la Administración del Estado, afectó también a las escuelas y a sus bibliotecas. La Guardia Civil, cada Ayuntamiento, la Falange o la Inspección de Primera Enseñanza fueron los brazos ejecutores de dicha incautación, que se mantuvo vigente hasta mediados de 1938. Por la Orden 16 de septiembre de 1937 se creaban la Comisiones Depuradoras de Bibliotecas, dependientes de su respectivo Distrito Universitario. Estas Comisiones aplicaron su tarea en todas

las bibliotecas públicas, populares, escolares y salas de lectura establecidas en casinos, sociedades recreativas, colegios, academias, en general, en cuantos Centros existan poseedores de bibliotecas o libros al servicio de cualquier clase de lectores $^{12}$.

Innumerables y curiosas son las acusaciones que se vierten sobre las antiguas Misiones republicanas por ejercer una labor "subversiva" entre las clases humildes de las que, a modo de ejemplo, citamos la que sigue. Proviene de Fernando Martín-Sánchez Juliá, ultracatólico fundador de la Universidad Internacional Menéndez Pelayo, y miembro de la Asociación Católica Nacional de Propagandistas (ACNdP):

Se lanzaron por España las 'Misiones pedagógicas' verdadero apostolado del diablo, corruptor de pueblos, enardecedor de revolucionarios de surco y esteva.

\footnotetext{
10 El Diputado Romualdo de Toledo, más tarde Director General de Primera Enseñanza, puso de manifiesto con varios párrafos literales su falta de imparcialidad, al denunciar que en las páginas 255 a 266 "se hace una exaltación clara del socialismo, del sindicalismo y del comunismo". El Ministro de Instrucción Pública, Joaquín Dualde, del Partido Liberal Demócrata, respondió que conocía el libro que "lo he leído y he de manifestar a S. S. que no me parece adecuado para la enseñanza, por lo cual lo retiraré". Véanse sus intervenciones en Diario de las Cortes del 27 de junio de 1935, citadas por Carmen Diego y Montserrat González (2008, p. 283-308).

11 Publicado el 16 de septiembre en el no 22 del Boletín Oficial de la Junta de Defensa Nacional. También puede consultarse, de Claudio LOZANO SEIJAS (1991, p. 294-295).

12 Véase Boletín oficial del Estado ํo 332 de 17 de septiembre de 1937.
} 
Repartiéronse 'bibliotecas populares' cuyos libros, comprados en masa por sectarios antiespañoles del Ministerio de Instrucción Pública, eran en gran parte manuales de anarquismo, obras neo-malthusianas o novelas revolucionarias, con las cuales se 'ilustró' a pobres campesinos que sólo sabían leer o a jóvenes obreros con ambiciones políticas [...]. (MARTíN-SÁNCHEZ JULIÁ, 1940, p. 113).

De hecho, el expurgo de las bibliotecas escolares se materializa poco después del golpe de estado, en 1936, al aplicarse estas medidas, con la intención de que las escuelas desterraran de las estanterías de sus bibliotecas todos los textos que no acatasen los valores nacional-católicos, como así lo aclaraba la circular enviada por el Secretario de la nueva institución:

Siendo una de las funciones más esenciales y urgentes de este Patronato (antes denominado de Misiones Pedagógicas) depurar las Bibliotecas por éste creadas con el fin de retirar aquellas obras cuyos autores o contenido en modo alguno deben continuar figurando en sus catálogos y queriendo no sólo que estos volúmenes recusables sean retirados y devueltos a este Patronato, sino también sustituirlos por otros que exalten los preciados ideales de nuestra Gloriosa Cruzada, le ruego se sirva devolverme cumplimentado el cuestionario adjunto y remitirnos a porte debido los libros que la Biblioteca de su dirección posea, comprendidos en la lista que se acompaña. ${ }^{13}$

En esta línea se inscribe la circular que difunde el Gobierno Civil de Pontevedra el 12 de septiembre de 1936 "sobre los libros de texto"14, por la que se pone en conocimiento de los maestros y maestras que deben enviar "en el plazo de tres días a los Inspectores de las respectivas zonas" la relación de los libros de texto y de lectura que guardan en las librerías de sus escuelas, comprendiendo el título, autor y fecha de su publicación; y otra aparte, de los que forman las Bibliotecas escolares, donde existan. El objeto era proceder "rápidamente" a elaborar "la selección de los libros que en adelante han de ser permitidos para la obra docente de la escuela". Pues como también se indica en la misma circular,

entre los factores que directamente contribuyen a la formación espiritual del niño figura el libro de texto y aún el de lectura, que, con la explicación oral del maestro van formando el gusto, el carácter y hasta la conciencia infantil, ejerciendo a veces tanta influencia un concepto aprendido y arraigado, que difícilmente la destruye ni a la misma autoridad del profesor". Por esta razón, "es de importancia suma que los libros que se ponen al alcance de los niños, tengan aquella orientación que requieren las conveniencias espirituales del alumno y reclaman a un mismo tiempo el bien de España y las necesidades del momento, que el movimiento militar salvador de la Patria está imprimiendo en todos sus preceptos. ${ }^{15}$

Ambas circulares tenían como punto de partida la Orden no 13 de 4 de septiembre de 1936, de "Incautación y destrucción" emitida por la Junta de Defensa Nacional desde Burgos (BO de la JDNE, 8 de septiembre de 1936), con las repercusiones consiguientes en la zona ocupada por los sublevados durante el segundo semestre de $1936^{16}$. Como

13 Circular emitida por el Patronato de Cultura Popular, aprox. 1941. Documento suelto sin paginar.
14 El Noticiero Gallego (Revista de Primera Enseñanza), no 2071, de 18 de septiembre de 1936.
15 lbidem.
16 La retórica reaccionaria del propio texto merece su transcripción literal: "La gestión del Ministerio de
Instrucción pública, y especialmente de la Dirección general de Primera Enseñanza, en éstos ( sic) últimos
años, no ha podido ser más perturbadora para la Infancia. Cubriéndola con un falso amor a la cultura, ha
apoyado la publicación de obras de carácter marxista o comunista, con las que ha organizado bibliotecas 
señala Borque López (1997, p. 32), su publicación, que pudiera resultar imprecisa en la propia redacción, al referirse a "libros presentes en bibliotecas ambulantes y escuelas", centraba su objetivo en las bibliotecas repartidas por el Patronato los años anteriores. A partir de la publicación de esta norma, todas las bibliotecas escolares fueron objeto de depuración. No solo las enviadas por el Patronato, sino también aquellas que, a pesar de ser escasas, ya existían con anterioridad.

En Pontevedra, el 3 de octubre de ese año, el Inspector Jefe Gerardo Álvarez Limeses, atenazado entre su catolicismo militante, su tenue galleguismo y la victimización política de parte de su familia a cargo de los franquistas, enviaba una circular a las escuelas de la provincia detallando la relación "de los libros autorizados provisionalmente por la Inspección de primera Enseñanza para uso en las escuelas nacionales en cumplimiento de lo dispuesto en la Orden núm. 13 de fecha 8 de septiembre de 1936 de la Junta de Defensa Nacional de España"17. De ese listado sólo coincide una obra con las que componen el catálogo de la Biblioteca de Misiones Pedagógicas de esta escuela: El Quijote.

A punto de comenzar el curso académico de 1938-39, se ordenó la retirada urgente de 60 libros "escritos con fines proselitistas doctrinalmente antipatrióticos y antirreligiosos, deficientes en el aspecto pedagógico 0 escritos por autores declaradamente enemigos del Glorioso Movimiento Nacional que actualmente ostentan cargos y desempeñan funciones de confianza a las órdenes del soviet de Barcelona". De ese conjunto, 32 habían sido aprobados por el Consejo de Instrucción Pública para su uso escolar hasta 1936, y tres de ellos estaban recomendados específicamente para su uso

ambulantes y de las que ha inundado las Escuelas, a costa del Tesoro público, constituyendo una labor funesta para la educación de la niñez. Es un caso de salud pública hacer desaparecer todas estas publicaciones, y para que no queden ni vestigios de las mismas, la Junta de Defensa Nacional ha acordado: Primero. Por los Gobernadores civiles, Alcaldes y Delegados gubernativos se procederá, urgente y rigurosamente, a la incautación y destrucción de cuantas obras de matiz socialista o comunista se hallen en bibliotecas ambulantes y escuelas. Segundo. Los Inspectores de Enseñanza adscritos a los Rectorados autorizarán, bajo su responsabilidad, el uso en las Escuelas únicamente de obras cuyo contenido responda a los sanos principios de la Religión y de la Moral cristiana, y que exalten con sus ejemplos el patriotismo de la niñez".

17 Se inserta la relación de obras tal como aparecen citadas en la circular: Lecciones de cosas, Dalmau; Deberes de los niños, Calleja; Virtud y Patria, Ruiz Romero; El Quijote, Cervantes; Enciclopedia escolar, Martí Alpera; Catecismo, P. Astete; Guía del artesano, Paluzie; Método de Rayas, Rodríguez Álvarez; Corazón, Amicis; Fábulas literarias, Samaniego; El Amigo, Pazzi; Enciclopedia, Ruiz Romero; Invenciones e inventores, Solana; Camarada, Dalmau; Historia de España, Calleja; Geografía idem; Gramática, A. de la Lengua; Enciclopedia, Porcel y Riera; El Cielo, Ascarza. Europa, Dalmau; Deberes, idem; El primer manuscrito, idem; Lecturas de Oro, Solana; Razas humanas, Ascarza; Recitaciones escolares, Solana; El Hombre, Ascarza; Historia de España, Solana; El Tesoro de las escuelas, Calleja; Nosotros, Blanco; Enciclopedia, Cami; Gramática, F.T.D.; Aritmética, idem; Historia Sagrada, Ruiz Romero; España mi Patria, Dalmau; Lecciones de cosas, Nualart; La niña instruida, Ascarza; Sancho Panza, Seix Barral; Centros de interés, Xandrí. Mentor, Ruiz Romero; Países y Mares, Plá; Enciclopedia, Dalmau; Concentraciones, Xandrí; Infancia, Dalmau; Catecismo histórico, Fleury; Lecciones de cosas, Porcel; La niña, Ascarza; Historia Sagrada, Solana; El continente antártico, Ascarza; El mundo exterior, Marinelo; Yo quiero saber leer, Solana; Mi cartilla, Trillo; Primer libro, Plá; Cartilla agrícola, Ascarza; Mi amigo el árbol, Martín Chico; Lecturas graduadas, F.T.D.; Primer libro de lecturas, Bruño. Lecciones de cosas, Bruño; Para mi hijo, Bustamante; El Trabajo, Maillo; Frases y cuentos, Aroca; Fábulas literarias, Iriarte; Lecciones de Lengua, Bruño; Aritmética, idem; Aritmética, Palau; Geometría, Paluzie; Geometría, G. Rodríguez; Geografía, Paluzie; Geografía, Bruño; Geografía, F.T.D.; Historia de España, Llano; Historia de España, F.T.D.; Historia de España, G. Rodríguez; Historia Sagrada, F.T.D.; Lecciones de cosas, Colomb. Historia Natural, Plá; Fisiología e Higiene, idem; Física y Química, idem; Agricultura, Boldu; Física elemental, Manent; Derecho, Gerardo Rodríguez; Nociones de Derecho, F.T.D.; Historia de España, Hueso; Geografía, idem; Lecturas Bíblicas, Solana. 
en las bibliotecas escolares. El resto podía haber llegado a las bibliotecas a través de un donativo particular, ser adquiridos por el maestro entre los recomendados por el Museo Pedagógico Nacional o proceder de los lotes enviados por el Patronato de Misiones Pedagógicas. (DIEGO PÉREZ; GONZÁLEZ FERNÁNDEZ, 2008).

El 30 de enero de 1938 se crea el Ministerio de Educación Nacional (nueva denominación, acorde con la ideología nacionalista, que sustituye a Instrucción Pública) y Romualdo de Toledo fue nombrado Director General de Primera Enseñanza y miembro de la "Comisión dictaminadora de los libros de texto que han de usar en las escuelas" por el ministro de Educación Nacional, Pedro Sainz Rodríguez. Éste despliega, durante su corta estancia al frente de la cartera, en el primer gobierno del régimen en febrero de 1938, toda una serie de medidas encaminadas a barrer los avances introducidos en el reconocimiento del bilingüismo, la coeducación y el laicismo, así como a imponer nuevas medidas correctoras que neutralizaran los avances anteriores, como la censura de los libros de texto, la depuración de los docentes, la derogación del decreto de expulsión de los jesuitas de 1931 y de la Ley de Confesiones y Congregaciones religiosas de 1933. De este modo, la Iglesia, que se había identificado con la "Santa Cruzada", recuperaba sus poderes políticos y pedagógicos tradicionales, al tiempo que confería legitimación al nacional-catolicismo beligerante y Franco le devolvía el favor de haberle ayudado a restablecer el 'orden y la estabilidad'.

A partir de julio de 1940, el Patronato de Cultura Popular acaba asumiendo las funciones del originario Patronato de Misiones Pedagógicas y poco después, ya en un nuevo tiempo, procede al envío de 1.546 nuevas bibliotecas a escuelas primarias públicas y privadas hasta mediados de 1942. En este escenario, radicalmente diferente, va a ser el Instituto San José de Calasanz, dependiente del CSIC, el responsable de su organización. El nuevo régimen aprovecha la idea y la infraestructura de las antiguas misiones, como refleja el artículo 32 de la Ley de Educación primaria de 17 de julio de 1945 (B.O.E. del 18) promovida por el ministro José Ibáñez Martín tras la destitución de Pedro Sainz Rodríguez. De este modo se reorienta el anterior proyecto, pasando a ser "instituciones organizadas por el Estado y el Movimiento para extender la cultura por los medios rurales" a través de numerosas actividades como "bibliotecas circulantes, conferencias, discotecas, exhibiciones teatrales, exposición de reproducciones artísticas, cine educativo, emisiones de radio y otros medios análogos".

El 1 de julio de 1941, Domingo Garcés recibe en su escuela una circular de la Sección de Bibliotecas del Patronato de Cultura Popular en la que se le informa de que, retirados ya los libros considerados "NO APTOS para su lectura" se procede al envío de "libros religiosos, libros históricos y libros del Movimiento, para completar el cuadro ideológico que debe figurar en toda biblioteca". El criterio a seguir, expresado en este documento es "poner en manos de los lectores aquellos libros de Literatura, Ciencia y Arte que mejor reflejen la vida española y manifiesten el genio de nuestro pueblo". Como antecedente, continúa el texto, "tomamos nuestros siglos XVI y XVII, cuyos grandes pensadores y escritores han de constituir certera orientación para valorar el pensamiento actual". Acababa el documento exhortando el celo de los maestros, como garantes del "fomento de la lectura en las localidades y barrios en donde todavía no ha nacido o arraigado el interés por el tesoro de la vida y alegría que encierran las Obras de nuestros 
grandes escritores"18.

Acabar con el analfabetismo de la población rural no era una prioridad esencial para Ibáñez Martín, que durante este periodo aplicó la política de sometimiento educativo a los intereses del régimen y de la Iglesia Católica y continuó con la depuración del Magisterio iniciada salvajemente tras el golpe de estado. La extensión de la lectura y de la cultura pasó a considerarse, desde presupuestos elitistas y paternalistas, algo superfluo, de puro entretenimiento, cuando no sospechoso por el contenido de los textos. Los mismos que se quejaban, o incluso se burlaban de la falta de preparación y de sensibilidad de los campesinos para comprender los libros, fueron los responsables de su eliminación y depuración durante la guerra y posterior dictadura. (MARTíNEZ RUS, 2013).

\section{El expurgo de la biblioteca de la escuela de Estás}

La Biblioteca de la escuela de Estás sufrió una depuración continuada que dio lugar a tres incautaciones. La primera mediante una circular emitida por la Inspección de Enseñanza Primaria, firmada por el Inspector Juan Novás Guillán el 6 de febrero de 1937. En este documento se insta a Domingo Garcés a

remitir los libros que forman parte de la Biblioteca enviada a su escuela por el Patronato de Misiones Pedagógicas, cuya relación se acompaña, para dar cumplimiento a lo dispuesto por la Superioridad, toda vez que pudieran no estar conformes con la modalidad impresa a la escuela española en los momentos actuales, procediendo en este caso a su destrucción. ${ }^{19}$

Por este primer procedimiento se depuran 12 obras (Cuadro 02), a las que hay que añadir otras dos (Mi vida, de Benvenuto Cellini y Dulce nombre, de Concha Espina) que no aparecen en el listado, pero ya habían sido retiradas por la Inspección, como así expresa Domingo Garcés al Inspector Juan Novás en nota escrita.

Cuadro 02 - Relación de obras retiradas el 18 de marzo de 1937 por orden de la Inspección de Enseñanza Primaria de 6 de febrero.

\begin{tabular}{|l|l|l|l|l|l|}
\hline & Título & Autor & & Título & Autor \\
\hline 23 & Sonata de estío & $\begin{array}{l}\text { Ramón del Valle } \\
\text { Inclán }\end{array}$ & 31 & $\begin{array}{l}\text { Cómo se forja un } \\
\text { pueblo }\end{array}$ & Rodolfo Llopis \\
\hline 25 & La ciudad de la niebla & Pío Baroja & 53 & Tigre Juan & $\begin{array}{l}\text { Ramón Pérez de } \\
\text { Ayala }\end{array}$ \\
\hline 26 & Cuentos Valencianos & Vicente Blasco lbáñez & 68 & El origen de la familia & Friedrich Engels \\
\hline 27 & $\begin{array}{l}\text { Crimen y castigo } \\
\text { (Tomo 1) }\end{array}$ & Fiódor Dostoieswki & 73 & La Celestina & Fernando de Rojas \\
\hline 28 & $\begin{array}{l}\text { Crimen y castigo } \\
\text { (Tomo 2) }\end{array}$ & Fiódor Dostoieswki & 77 & Notas & José Ortega y Gasset \\
\hline 29 & Mis memorias & Leon Tolstoy & 80 & Sachka Yegulev & Leónidas Andreiev \\
\hline
\end{tabular}

Fuente: elaboración propia a partir de la documentación contenida en el expediente que se conserva en el archivo de la escuela.

18 PATRONATO DE CULTURA POPULAR, "A los señores maestros depositarios de bibliotecas". Documento suelto sin paginar.

${ }^{19}$ Circular remitida por el Inspector Juan Novás Guillán, con fecha 6 de febrero de 1937. Documento suelto sin paginar. 
En esta primera depuración aparecen, los escritores rusos Fiódor Dostoieswki, Leónidas Andreiev y Leon Tolstoy ${ }^{20}$. Y en este grupo debemos incluir al alemán Friedrich Engels, coautor con Marx de obras fundamentales para el nacimiento de los movimientos obreros ligados al socialismo revolucionario y dirigente político de la Primera y Segunda Internacional. El caso de la española Concha Espina, se explica seguramente por el hecho de haber fundado en 1933 la Asociación de Amigos de la Unión Soviética, motivo más que suficiente, por "conducta subversiva", para la retirada de sus obras, en línea con la Orden núm. 13 de fecha 8 de septiembre de 1936 de la Junta de Defensa Nacional de España, a la que aludíamos en páginas anteriores.

En otros autores podemos entender que el motivo sea, sin duda, su vinculación republicana, caso de Ramón del Valle Inclán, Vicente Blasco Ibáñez o José Ortega y Gasset; o su adscripción institucionista, si nos referimos a Rodolfo Llopis o a Ramón Pérez de Ayala. Con respecto a Pío Baroja, podrían haberse considerado sus antecedentes políticos ${ }^{21}$. En todo caso, en su conjunto pesa la acusación de ser autores "declaradamente enemigos del Glorioso Movimiento Nacional". Por último, el caso de Fernando de Rojas y La Celestina debe estar relacionado con el género de la obra, "deficiente en el aspecto pedagógico", por más que el Bachiller la hubiese concebido con una intención moralizante, aspecto que no parecen conocer, o entender, sus censores.

La segunda depuración se produce a raíz de la orden emitida por la citada Inspección el 30 de agosto de 1938 por la que se retiran dos libros más: Flor de leyendas, de Alejandro Casona, y Curiosos pobladores del mar, de Enrique Rioja Lo Bianco. Estas obras, según apunte manuscrito del maestro, habían sido enviadas a la Inspección en virtud de Orden de la jefatura del Servicio Nacional de Primera Enseñanza el 12 de septiembre de 1938, cumpliendo lo indicado. En ambos casos, y a pesar de su valor pedagógico, pesó la vinculación de sus autores a las Misiones Pedagógicas y la ILE²2. Curiosos pobladores del mar de Enrique Rioja Lo Bianco, miembro también del Patronado de Misiones, fue declarada obra de interés en las bibliotecas escolares y se publicó en varios países de habla hispana ${ }^{23}$.

La tercera depuración tiene origen en la circular de 10 de julio de 1940, del nuevo Patronato de Cultura Popular, por la que se dan de baja otros 17 títulos, que se envían a

${ }^{20}$ La nacionalidad de estos tres autores, la referencia a Rusia y el temor al marxismo y al socialismo son, sin duda, la causa de que sus obras figuren entre las "no conformes", junto con Friedrich Engels y Concha Espina. Los dos primeros fueron, de alguna forma, acicates de las luchas populares rusas; Tolstoy, más en la órbita del pensamiento anarquista, fundó la escuela Yasnaia Poliana, considerada uno de los precedentes del movimiento de la Escuela Nueva y donde llevó a cabo una pedagogía en algún punto libertaria.

${ }^{21}$ Pío Baroja se había presentado en Madrid, en 1909, como concejal lerrouxista y como diputado en Fraga, Huesca, y había integrado junto con Azorín y Ramiro de Maeztu el llamado "Grupo de los tres" literatos de ideología anarquista.

22 Es necesario resaltar que Flor de Leyendas, compendio de obras clásicas de la literatura universal adaptadas a la infancia, fue un trabajo por el que el inspector de primera enseñanza y director del Teatro del Pueblo de las Misiones había recibido el Premio Nacional de Literatura en 1932. Como recuerda Carmen Diego (1999), tanto la prensa general como la prensa pedagógica y profesional se hicieron eco de las bondades de la adaptación de Casona, reseñándola en 1933 las principales revistas de educación: Revista de Pedagogía (no 138), Escuelas de España (no 98) y Revista Escuelas Normales (no 98).

${ }^{23}$ Editada en Madrid por Espasa Calpe en 1929, había sido aprobada por el Consejo de Instrucción Pública para uso en bibliotecas escolares. Finalizada la Guerra, el editor solicitó de nuevo su evaluación omitiendo el nombre del autor, y curiosamente fue aprobada por la Sección Tercera del Consejo Nacional de Educación, el 6 de mayo de 1943 en el Boletín Oficial del Ministerio de Educación Nacional del 12 de junio de ese año. Llegó a su séptima edición en 1962. 
la nueva sede (Avda. del Generalísimo, 21) "por gran velocidad y a porte debido" según indica el propio maestro. Este lote integra un conjunto variado de obras, autores y estilos (Cuadro 03).

Cuadro 03 - Relación de obras retiradas el 10 de julio de 1940.

\begin{tabular}{|c|l|l|l|l|l|}
\hline & Título & Autor & & Título & Autor \\
\hline 4 & Quintín Duwart & Walter Scott & 66 & $\begin{array}{l}\text { Viaje sentimental de } \\
\text { un inglés a Francia }\end{array}$ & Laurence Sterne \\
\hline 6 & $\begin{array}{l}\text { La luna nueva. } \\
\text { Poemas de niños }\end{array}$ & R. Tagore & 74 & $\begin{array}{l}\text { La Cartuja de Parma } \\
\text { (Tomo 1) }\end{array}$ & Henri Beyle Stendhal \\
\hline 10 & $\begin{array}{l}\text { Estudios sobre } \\
\text { educación }\end{array}$ & Francisco Giner & 75 & $\begin{array}{l}\text { La Cartuja de Parma } \\
\text { (Tomo 2) }\end{array}$ & Henri Beyle Stendhal \\
\hline 13 & Obras dramáticas & Friedrich Schiller & 76 & Papá Goriot & Honoré de Balzac \\
\hline 16 & Platero y yo & Juan R. Jiménez & 78 & El Asno de Oro & Lucio Apuleyo \\
\hline 43 & $\begin{array}{l}\text { Figuras de la Pasión } \\
\text { del Señor }\end{array}$ & Gabriel Miró & 82 & $\begin{array}{l}\text { Historia de la } \\
\text { civilización española }\end{array}$ & Rafael Altamira \\
\hline 52 & Pepita Giménez & Juan Valera & 89 & $\begin{array}{l}\text { La educación } \\
\text { sentimental (Tomo 1) }\end{array}$ & Gustave Flauvert \\
\hline 65 & $\begin{array}{l}\text { Las Escuelas Nuevas } \\
\text { Norteamericanas }\end{array}$ & Fernando Sáinz & 90 & $\begin{array}{l}\text { La educación } \\
\text { sentimental (Tomo 2) }\end{array}$ & Gustave Flauvert \\
\hline
\end{tabular}

Fuente: elaboración propia a partir de la documentación contenida en el expediente que se conserva en el archivo de la escuela.

En la lógica siempre interpretable de los censores se encuentra la baja de los textos de los institucionistas, por el mero hecho de serlo, Francisco Giner (Sobre la educación), Fernando Sáinz (Las Escuelas Nuevas norteamericanas), Rafael Altamira (Historia de la Civilización española) o Juan Ramón Jiménez (Platero y yo). Además de éstos, también se retiran las obras de cuatro autores franceses. Intuimos, también, que por el hecho de serlo: Friedrich Schiller (Obras dramáticas), Gustave Flauvert (La educación sentimental), Honoré de Balzac (Papá Goriot) o Henri Beyle Stendhal (La Cartuja de Parma). Tampoco se salvó de la censura El asno de oro, del clásico Lucio Apuleyo. Probablemente por ser un texto crítico e irreverente a ojos de los censores, antecedente de la novela picaresca, que se desarrolla en el contexto pagano de la Roma clásica, y por lo tanto, también, "deficiente en el aspecto pedagógico". Por último, Juan Ramón Jiménez, y especialmente su esposa Zenobia Campubrí habían traducido algunas obras de Rabindranat Tagore, entre ellas La luna nueva, poemas de niños. Un hecho que quizá explique la decisión de apartar del catálogo esta obra del Nobel bengalí de Literatura en 1913. Además de éstos, se purga a Gabriel Miró (Figuras de la pasión del Señor) y Juan Valera (Pepita Giménez), cuyo criterio debió estar condicionado por el carácter "doctrinalmente antipatriótico" de sus trabajos. Tampoco se salva Quintín Duwart, de Walter Scott, aunque no tengamos una explicación clara para esta baja.

Tampoco la tenemos para explicar que se salvaran de la purga Cuentos de Marineda, de Emilia Pardo Bazán, una luchadora por la emancipación social e intelectual de la mujer, próxima además a la ILE; o Poesía en prosa y verso, de Juan Ramón Jiménez habiendo sido depurada, del mismo autor, Platero y yo. En relación a Ideario de 
Costa de José García Mercadal (Biblioteca nueva, 1932), que tampoco fue requisada, puede entenderse porque, pese a tratar las ideas del más destacado regeneracionista, García Mercadal acabó siendo un eficiente polígrafo reconvertido a la causa nacional a partir de la guerra civil.

En este contexto de altas y bajas, el maestro Domingo Garcés remite un informe con el recuento de obras retiradas en las tres depuraciones, fechado el 10 de julio de 1940 y en el mismo se atreve a sugerir al Patronato, siguiendo la retórica impuesta, y tratando de anticiparse al nuevo envío anunciado, que

\begin{abstract}
además de los libros referentes a nuestra Gloriosa Cruzada, que en su cartacircular indica se nos enviarán, sustituyendo a los que se retiran de las bibliotecas, me atrevo a manifestarle que vería con gusto se me enviasen más libros propios para niños, como cuentos instructivos y lecciones de cosas, muy útiles en el medio rural, donde hay que sustituir la falta de vista de muchas cosas de las ciudades por la lectura razonada y variada, así como obras referentes a labores agrícolas, lo que interesa a las personas mayores, y no cabe duda que ayuda al labrador a mejorar sus cultivos. ${ }^{24}$
\end{abstract}

Al mismo tiempo, en la primera semana de julio de 1941 el nuevo Patronato de Cultura Popular envía una serie de libros (Cuadro 04) que habían de sustituir a los anteriores, quedando al final la Biblioteca, el 12 de julio de 1941, tal como muestra el Cuadro 05.

Cuadro 04 - Relación de obras enviadas por el Patronato de Cultura Popular recibidas os días 1 e 8 de julio de 1941.

\begin{tabular}{|l|l|l|c|l|l|}
\hline & Título & Autor & & Título & Autor \\
\hline 1 & $\begin{array}{l}\text { Vida de San } \\
\text { Fernando, Rey de } \\
\text { España }\end{array}$ & $\begin{array}{l}\text { Apostolado de la } \\
\text { prensa }\end{array}$ & 14 & $\begin{array}{l}\text { Glorias Imperiales } \\
\text { (Tomo 1) }\end{array}$ & Luis Ortiz Muñoz \\
\hline 2 & $\begin{array}{l}\text { Vida de San Pedro } \\
\text { Claver }\end{array}$ & $\begin{array}{l}\text { Apostolado de la } \\
\text { prensa }\end{array}$ & 15 & $\begin{array}{l}\text { Glorias Imperiales } \\
\text { (Tomo 2) }\end{array}$ & Luis Ortiz Muñoz \\
\hline 3 & $\begin{array}{l}\text { Vida de San Vicente } \\
\text { Ferrer }\end{array}$ & $\begin{array}{l}\text { Apostolado de la } \\
\text { prensa }\end{array}$ & 16 & $\begin{array}{l}\text { La Virgen María. } \\
\text { Aurora de Salvación }\end{array}$ & P. Gaspar G. Pintado \\
\hline 4 & $\begin{array}{l}\text { P. Mariana. Pensador } \\
\text { y político (Tomo 2) }\end{array}$ & $\begin{array}{l}\text { M. Ballesteros } \\
\text { Gaibrois }\end{array}$ & 17 & $\begin{array}{l}\text { Misa dialogada- } \\
\text { cantada }\end{array}$ & P. Martínez Díaz \\
\hline 5 & Laureados (Tomo 1) & Bonilla y Viladamat & 18 & Para los niños & P. Javier Poveda \\
\hline 6 & Laureados (Tomo 2) & Bonilla y Vilademat & 19 & Devocionario popular & P. Remigio Vilariño \\
\hline 7 & Palabras del Caudillo & Ediciones F. E. & 20 & $\begin{array}{l}\text { Los caminos de } \\
\text { Jesucristo }\end{array}$ & P. Remigio Vilariño \\
\hline 8 & $\begin{array}{l}\text { Símbolos de España. } \\
\text { Libro escolar de } \\
\text { lectura }\end{array}$ & El Magisterio Español & 21 & $\begin{array}{l}\text { Obras Completas. } \\
\text { Discursos. Tomo 1. }\end{array}$ & J. A. Primo de Rivera \\
\hline 9 & Discursos & R. Fernández Cuesta & 22 & El Estado Nacional & Onésimo Redondo \\
\hline 10 & $\begin{array}{l}\text { Hernal Díaz del } \\
\text { Castillo. Antología }\end{array}$ & $\begin{array}{l}\text { Darío Fernández } \\
\text { Flórez }\end{array}$ & 23 & Obra Completa & Julio Ruiz de Alda \\
\hline
\end{tabular}

${ }^{24}$ Carta-Informe remitido por Domingo Garcés al Secretario del Patronato de Cultura Popular, con fecha 15 de julio de 1940. Documento suelto sin paginar. 


\begin{tabular}{|c|l|l|l|l|l|}
\hline & Título & Autor & & Título & Autor \\
\hline 11 & San Isidoro. Antología & Fray Pérez de Urgel & 24 & $\begin{array}{l}\text { De la Victoria y la } \\
\text { Postguerra. Discursos }\end{array}$ & R. Serrano Suñer \\
\hline 12 & $\begin{array}{l}\text { Discurso a las } \\
\text { juventudes de España }\end{array}$ & R. Ledesma Ramos & 25 & $\begin{array}{l}\text { José Antonio Primo de } \\
\text { Rivera. Antología }\end{array}$ & G. Torrente Ballester \\
\hline 13 & $\begin{array}{l}\text { Ramiro Ledesma } \\
\text { Ramos. Antología }\end{array}$ & Antonio Macipe López & 26 & $\begin{array}{l}\text { Predicciones. } \\
\text { Antología }\end{array}$ & J. Vázquez de Mella \\
\hline
\end{tabular}

Fuente: elaboración propia a partir de la documentación contenida en el expediente que se conserva en el archivo de la escuela.

Cuadro 05 - Composición definitiva de la Biblioteca después del expurgo, según relación de obras remitida desde la escuela nacional de Estás (Tomiño) a la Sección de Bibliotecas del Patronato de Cultura Popular con fecha 12 de julio de 1941.

\begin{tabular}{|c|c|c|c|c|c|}
\hline & Título & Autor & & Título & Autor \\
\hline 1 & $\begin{array}{l}\text { Las Escuelas Nuevas } \\
\text { italianas }\end{array}$ & Concepción. S. Amor & 46 & $\begin{array}{l}\text { Ramiro Ledesma } \\
\text { Ramos. Antología }\end{array}$ & Antonio Macipe López \\
\hline 2 & $\begin{array}{l}\text { Cuentos de los } \\
\text { Juguetes Vivos }\end{array}$ & Antonio Robles & 47 & Poesías completas & Antonio Machado \\
\hline 3 & $\begin{array}{l}\text { Vida de San } \\
\text { Fernando, rey de } \\
\text { España }\end{array}$ & $\begin{array}{l}\text { Apostolado de la } \\
\text { prensa }\end{array}$ & 48 & Miguel Servet & A. Martínez \\
\hline 4 & $\begin{array}{l}\text { Vida de San Pedro } \\
\text { Claver }\end{array}$ & $\begin{array}{l}\text { Apostolado de la } \\
\text { prensa }\end{array}$ & 49 & $\begin{array}{l}\text { Las cien mejores } \\
\text { poesías }\end{array}$ & $\begin{array}{l}\text { Selección de M. } \\
\text { Pelayo }\end{array}$ \\
\hline 5 & $\begin{array}{l}\text { Vida de San Vicente } \\
\text { Ferrer }\end{array}$ & $\begin{array}{l}\text { Apostolado de la } \\
\text { prensa }\end{array}$ & 50 & $\begin{array}{l}\text { El enfermo de } \\
\text { aprensión }\end{array}$ & Moliére \\
\hline 6 & $\begin{array}{l}\text { P. Mariana. Pensador } \\
\text { y político (Tomo 2) }\end{array}$ & $\begin{array}{l}\text { M. Ballesteros } \\
\text { Gaibrois }\end{array}$ & 51 & Comedias & Agustín Moreto \\
\hline 7 & Obras escogidas & $\begin{array}{l}\text { Gustavo Adolfo } \\
\text { Bécquer }\end{array}$ & 52 & $\begin{array}{l}\text { Guía del Horticultor. } \\
\text { La huerta y el corral }\end{array}$ & Juan Nonell \\
\hline 8 & Laureados (Tomo 1) & Bonilla y Vilademat & 53 & $\begin{array}{l}\text { Glorias Imperiales } \\
\text { (Tomo 1) }\end{array}$ & Luis Ortiz Muñoz \\
\hline 9 & Laureados (Tomo 2) & Bonilla y Vilademat & 54 & $\begin{array}{l}\text { Glorias Imperiales } \\
\text { (Tomo 2) }\end{array}$ & Luis Ortiz Muñoz \\
\hline 10 & La navegación & A. Cabrera & 55 & $\begin{array}{l}\text { La Virgen María. } \\
\text { Aurora de Salvación }\end{array}$ & P. Gaspar G. Pintado \\
\hline 11 & Teatro & Calderon de la Barca & 56 & Misa dialogada & P. Martínez Díaz \\
\hline 12 & El almacén de cuentos & Saturnino Calleja & 57 & Para los niños & P. Poveda \\
\hline 13 & $\begin{array}{l}\text { Sucesos } \\
\text { extraordinarios }\end{array}$ & Saturnino Calleja & 58 & Devocionario popular & P. Vilariño \\
\hline 14 & Los Lusíadas & Luiz de Camoens & 59 & $\begin{array}{l}\text { Los caminos de } \\
\text { Jesucristo }\end{array}$ & P. Vilariño \\
\hline 15 & $\begin{array}{l}\text { Alicia en el País de las } \\
\text { Maravillas }\end{array}$ & Lewis Carrol & 60 & $\begin{array}{l}\text { Geografía de España } \\
\text { y Portugal }\end{array}$ & Joan Palau Vera \\
\hline 16 & $\begin{array}{l}\text { D. Quijote de la } \\
\text { Mancha }\end{array}$ & Miguel de Cervantes & 61 & Geografía Humana & Joan Palau Vera \\
\hline 17 & Júbilos & C. Conde & 62 & $\begin{array}{l}\text { Vida de Alejandro } \\
\text { Magno }\end{array}$ & Joan Palau Vera \\
\hline
\end{tabular}




\begin{tabular}{|c|c|c|c|c|c|}
\hline & Título & Autor & & Título & Autor \\
\hline 18 & El lazarillo de Tormes & Anónimo & 63 & $\begin{array}{l}\text { Vida de Cristóbal } \\
\text { Colón }\end{array}$ & Joan Palau Vera \\
\hline 19 & Grandes llusiones & Charles Dickens & 64 & Vida de Stephenson & Joan Palau Vera \\
\hline 20 & El Conde Lucanor & Don Juan Manuel & 65 & Vida de Julio César & Joan Palau Vera \\
\hline 21 & $\begin{array}{l}\text { El Moro Expósito } \\
\text { (Tomo 1) }\end{array}$ & Duque de Rivas & 66 & Cuentos de Marineda & Emilia Pardo Bazán \\
\hline 22 & $\begin{array}{l}\text { El Moro Expósito } \\
\text { (Tomo 2) }\end{array}$ & Duque de Rivas & 67 & $\begin{array}{l}\text { Lecturas geográficas I. } \\
\text { Asia y África }\end{array}$ & Diego Pastor \\
\hline 23 & Atlas Universal & Edelvides & 68 & $\begin{array}{l}\text { Lecturas geográficas } \\
\text { II. América y Oceanía }\end{array}$ & Diego Pastor \\
\hline 24 & Palabras del Caudillo & Ediciones F. E. & 69 & $\begin{array}{l}\text { Lecturas geográficas } \\
\text { III. Europa }\end{array}$ & Diego Pastor \\
\hline 25 & Símbolos de España & El Magisterio Español & 70 & $\begin{array}{l}\text { Lecturas geográficas } \\
\text { IV. España y Portugal }\end{array}$ & Diego Pastor \\
\hline 26 & Abejas y Colmenas & $\begin{array}{l}\text { F. Martínez Escalera, } \\
\text { E. Suja }\end{array}$ & 71 & El sabor de la tierruca & José María de Pereda \\
\hline 27 & Poesías & José de Espronceda & 72 & $\begin{array}{l}\text { Cómo enseña } \\
\text { Gertrudis a sus hijos }\end{array}$ & Johann H. Pestalozzi \\
\hline 28 & Discursos & R. Fernández Cuesta & 73 & $\begin{array}{l}\text { Obras Completas. } \\
\text { Discursos. Tomo } 1 .\end{array}$ & J. A. Primo de Rivera \\
\hline 29 & $\begin{array}{l}\text { Hernal Díaz del } \\
\text { Castillo. Antología }\end{array}$ & $\begin{array}{l}\text { Darío Fernández } \\
\text { Flórez }\end{array}$ & 74 & $\begin{array}{l}\text { Los sueños I-II (Tomo } \\
\text { 1) }\end{array}$ & Francisco de Quevedo \\
\hline 30 & $\begin{array}{l}\text { Artículos de } \\
\text { costumbres (Tomo 1) }\end{array}$ & Mariano José de Larra & 75 & $\begin{array}{l}\text { Los sueños III (Tomo } \\
\text { 2) }\end{array}$ & Francisco de Quevedo \\
\hline 31 & $\begin{array}{l}\text { Artículos de } \\
\text { costumbres (Tomo 2) }\end{array}$ & Mariano José de Larra & 76 & El Estado Nacional & Onésimo Redondo \\
\hline 32 & San Isidoro. Antología & Fray Pérez de Urgel & 77 & Obra Completa & Julio Ruiz de Alda \\
\hline 33 & $\begin{array}{l}\text { Diccionario } \\
\text { Enciclopédico } \\
\text { llustrado }\end{array}$ & La Fuente & 78 & Los meteoros & E. Sema \\
\hline 34 & $\begin{array}{l}\text { Historias de Hans } \\
\text { Andersen }\end{array}$ & Mary McGregor & 79 & $\begin{array}{l}\text { De la Victoria y la } \\
\text { Postguerra. Discursos }\end{array}$ & Ramón Serrano Suñer \\
\hline 35 & Los Héroes & Mary McGregor & 80 & Obras Completas & William Shakespeare \\
\hline 36 & $\begin{array}{l}\text { El tonelero de } \\
\text { Nuremberg }\end{array}$ & Ernst T. A. Hoffmann & 81 & $\begin{array}{l}\text { Cien romances } \\
\text { escogidos }\end{array}$ & Antonio G. Solalinde \\
\hline 37 & Ilíada (Tomo 1) & Homero & 82 & La Isla del Tesoro & $\begin{array}{l}\text { Robert Louis } \\
\text { Stevenson }\end{array}$ \\
\hline 38 & Ilíada (Tomo 2) & Homero & 83 & La vida de los Astros & José Tinoco \\
\hline 39 & $\begin{array}{l}\text { Los trabajadores del } \\
\text { mar }\end{array}$ & Víctor Hugo & 84 & $\begin{array}{l}\text { José Antonio Primo de } \\
\text { Rivera. Antología }\end{array}$ & G. Torrente Ballester \\
\hline 40 & $\begin{array}{l}\text { Cuentos de la } \\
\text { Alhambra }\end{array}$ & Washington Irving & 85 & $\begin{array}{l}\text { Vida y desventuras de } \\
\text { M. de Cervantes }\end{array}$ & Mariano Tomás \\
\hline 41 & $\begin{array}{l}\text { Poesía en prosa y } \\
\text { verso }\end{array}$ & Juan Ramón Jiménez & 86 & Nuestro organismo & Juan Vázquez \\
\hline 42 & $\begin{array}{l}\text { Historia de la } \\
\text { arquitectura cristiana }\end{array}$ & V. Lampérez y Romea & 87 & $\begin{array}{l}\text { Predicciones. } \\
\text { Antología }\end{array}$ & $\begin{array}{l}\text { Juan Vázquez de } \\
\text { Mella }\end{array}$ \\
\hline
\end{tabular}




\begin{tabular}{|c|l|l|l|l|l|}
\hline & Título & Autor & & Título & Autor \\
\hline 43 & $\begin{array}{l}\text { Cómo se elige un } \\
\text { arado }\end{array}$ & José Cruz Lapazarán & 88 & $\begin{array}{l}\text { La fotografía y el } \\
\text { cinematógrafo }\end{array}$ & V. Vera \\
\hline 44 & $\begin{array}{l}\text { Discurso a las } \\
\text { juventudes de España }\end{array}$ & $\begin{array}{l}\text { Ramiro Ledesma } \\
\text { Ramos }\end{array}$ & 89 & $\begin{array}{l}\text { Cinco semanas en } \\
\text { globo }\end{array}$ & Julio Verne \\
\hline 45 & $\begin{array}{l}\text { Peribáñez y el } \\
\text { Comendador de } \\
\text { Ocaña }\end{array}$ & V. Lampérez y Romea & & & \\
\hline
\end{tabular}

Fuente: elaboración propia a partir de la documentación contenida en el expediente que se conserva en el archivo de la escuela.

Entre las incorporaciones, y para tratar de explicar la contundencia y dimensión ideológica del expurgo, queremos detenernos en las características de los libros seleccionados teniendo en cuenta autores, temática y editoriales. Podemos clasificar las obras en dos únicos apartados, que comparten una naturaleza densamente doctrinaria: de un lado los de contenido político y de otro los de contenido religioso católico, con un objetivo común, que no es otro que el que expresa la Orden de 4 de septiembre de 1936, a la que ya hemos aludido: "Obras cuyo contenido responda a los santos principios de la religión y de la Moral cristiana, y que exalten con sus ejemplos el patriotismo de la niñez". En este sentido, no deja de ser un claro ejemplo de lo que será la futura política del libro escolar: "la subordinación de los libros de texto al dogma y a la moral católicos, así como una unilateral y exclusiva consideración del patriotismo". (PUELLES BENÍTEZ, 1998, p. 52).

Empezando por los libros de contenido político, citamos, en primer lugar, Discurso a las Juventudes de España, de Ramiro Ledesma Ramos, publicado por Ediciones de La Conquista del Estado, Madrid, 1935 y posteriormente en la Editorial FE (1938 y siguientes). Como nos recuerda Ferrán Gallego (2005), es la obra política capital de Ledesma Ramos, y el texto teórico fundamental del fascismo español. Contiene una interpretación de la historia de España, un proyecto político de carácter nacionalista y totalitario, y una táctica precisa para la conquista del poder. Igualmente, destaca su innovadora interpretación del fenómeno fascista. ${ }^{25}$

De la Delegación Nacional de Prensa y Propaganda de FET y de las JONS, con el sello Editorial FE se elige varios libros. En primer lugar, Palabras del Caudillo, una especie de manual escolar considerado de formación política, didáctica y adoctrinadora, ya que se utilizaba en las escuelas para la formación del alumnado. De la misma editorial se incluye Discursos, de Raimundo Fernández Cuesta, Secretario General de Falange y más tarde Secretario General del Movimiento, además de ministro de varias carteras y

\footnotetext{
25 En este libro se encuentra una parte muy considerable del contenido doctrinal del nacional-sindicalismo español: el antiliberalismo, la apelación a las masas trabajadoras y a las juventudes, la economía dirigida, etc. El propio Ledesma Ramos afirma en una "Nota previa" de la edición original, fechada en mayo de 1935 (p. 9), "descubrir para España una perspectiva histórica y política, que se nutriese a la vez de las dos únicas palancas hoy de veras eficaces para hacer de España lo que esta generación debe conseguir que sea: una Patria justa, grande y liberadora. He aquí esas dos palancas: una, la idea nacional, la Patria como empresa histórica y como garantía de existencia histórica de todos los españoles; otra, la idea social, la economía socialista, como garantía del pan y del bienestar económico de todo el pueblo. Me cupo, al parecer, la tarea de unificar esas dos banderas, dotarlas de los símbolos emocionales necesarios y señalar y poner las piedras primeras de una organización que las interpretase. Todo eso ya está ahí, anda por España, y creo que de un modo insoslayable y visible. Son las J.O.N.S.".
} 
embajador de España. Se suman a los anteriores, de la colección "Breviarios del pensamiento español": San Isidoro (Antología), de Justo Pérez de Urbel y Timoteo Ortega; Ramiro Ledesma Ramos. Antología, con edición y prólogo de Antonio Macipe López; P. Mariana. Pensador y político, con selección y estudio a cargo de Manuel Ballesteros-Gaibrois. Además de éstos, de la misma editorial: José Antonio Primo de Rivera. Antología, con selección y prólogo a cargo de Gonzalo Torrente Ballester, literato gallego, que a pesar de haber militado en el Partido Galeguista y frecuentar los círculos literarios republicanos prebélicos, acabó afiliándose a Falange en 1937. El Estado Nacional, de Onésimo Redondo, dirigente nacional-sindicalista, fundador de las Juntas Castellanas de Actuación Hispánica, de ideología fascista, que acabó fundiéndose en 1931 con Falange; Obra completa, de Julio Ruiz de Alda Miquelei, afamado aviador, con protagonismo en el vuelo que realiza de Palos de la Frontera a Buenos Aires en compañía de Ramón Franco. Cofundador de Falange junto a José Antonio, galardonado por Alfonso XIII y el propio Mussolini. Se recogen un número significativo de discursos pronunciados entre 1933 y 1936, y varias conferencias y escritos sobre su visión del ejército, la aviación o el régimen nacional-sindicalista; y De la Victoria y la Postguerra. (Discursos), de Ramón Serrano Suñer, cuñado del dictador y uno de los artífices, desde varios ministerios, de la organización del Régimen en su estructura política. Por último, Antología, compendio de textos de Bernal Díaz del Castillo (1492-1585), conquistador en América y cronista de Indias. Obra con edición y prólogo a cargo de Darío Fernández Flórez, integrante de la Vicesecretaría de Educación Popular de FET y de las JONS, además de censor. Con prólogo de Raimundo Fernández Cuesta figura Obras Completas. Discursos, Tomo I., de José Antonio Primo de Rivera, editada por Editorial Arriba, de Bilbao.

De la editorial El Magisterio Español se eligen dos obras. Hablamos en primer lugar de Símbolos de España, libro escolar de lectura, de Luis Ortiz Muñoz, (1905-1975), Catedrático de Griego y Latín y fundador y director del Instituto Ramiro de Maeztu. Gozó de importantes cargos políticos como Director General de Enseñanza Media y Universitaria, Subsecretario de Educación Popular y Procurador en Cortes, además de periodista en El Debate, El Correo de Andalucía, Ya y Magisterio Español. Símbolos de España es un compendio de lecturas "patrióticas" de aplicación escolar, tal como expresa una leyenda en su portada: "Para todos los grados que sepan leer, sean de niños o de niñas". Anterior al texto aparece un breve inciso del autor animando a los escolares a memorizar las lecturas del libro, para que sean "acendradamente españoles". El otro texto, Glorias Imperiales. Libro de lecturas históricas, del mismo autor. Se trata de uno de los libros más populares de lecturas patrióticas en el que se resaltan los valores de la raza a través de episodios gloriosos y hechos heroicos. Se enfatiza la unidad social, política y religiosa, forjada por los Reyes Católicos; la conquista y la colonización de América; se rememora el pasado imperial de la España de Carlos V y Felipe II y se subrayan la Inquisición y la Contrarreforma (ASENSI DÍAZ, 2009, p. 44). A éstos hay que añadir, además, los dos volúmenes de Laureados (Ediciones Cigüeña, San Sebastián). En este libro se ensalzan acontecimientos y protagonistas de la guerra civil narrados para un público infantil por Álvaro Cunqueiro y Antonio de Obregón con ilustraciones a color de José Picó, Eduardo Santonja y Domingo Viladomat.

En el segundo grupo se incluyen aquellos dedicados a propagar un modelo de Estado "integrista de carácter tradicionalista" desde la vertiente religiosa, si seguimos la 
expresión de Puelles Benítez (1998, p. 50). De la editorial Apostolado de la Prensa se eligen tres libros, de una serie sobre vidas de santos (San Fernando rey de España, San Pedro Claver, San Vicente Ferrer), de autoría anónima ${ }^{26}$.

De la editorial católica El Mensajero del Corazón de Jesús aparece Devocionario popular; Los caminos de Jesucristo, de Remigio Vilariño, religioso jesuíta y director de la publicación homónima. Para los niños, de Javier Poveda Castroverde (Padre Poveda) ${ }^{27}$, un sacerdote vinculado al mundo de la educación, asesinado en las tapias del cementerio madrileño de la Almudena; Misa dialogada-cantada, del P. Martínez Díaz, y La Virgen María. Aurora de Salvación del P. Gaspar G. Pintado. Por último, del Instituto Editorial Reus, de Madrid, se elige Predicciones de Vázquez de Mella: antología del verbo de la tradición, de Juan Vázquez de Mella y Fanjul.

\section{A modo de conclusión}

El período democrático que se vivió entre 1931 y 1936, especialmente el bienio azañista, quiso iniciar una nueva política educativa basada en la búsqueda de la equidad social a través de la oportunidad cultural: transformar la sociedad democratizando la cultura y facilitando su acceso a las clases más humildes. Una tarea que se vio frustrada a partir de la sublevación, en la zona ocupada, y después de 1939 en el resto del Estado.

Para Manuel Bartolomé Cossío, presidente del Patronato, y María Moliner, responsable de la política bibliotecaria durante la República, la difusión cultural a través de las bibliotecas populares debía materializar el necesario encuentro, secularmente postergado, entre las clases populares y el ejercicio de la democracia como un derecho sentido. Las bibliotecas debían responder a una intención generalista, funcional y práctica, pensada con criterio pedagógico. Pero también con una honesta vocación social, y una comprensible intencionalidad política, que tenía por objeto, en su conjunto, mostrar, ofrecer, proporcionar formación, además de información, a través de la lectura a un contexto donde nunca antes había llegado; estimular hábitos de lectura y, a partir de ahí ampliar horizontes para llegar al conocimiento sobre la existencia de otras realidades, más allá del atrio de la iglesia o del balcón municipal. Un objetivo que, por otro lado, tampoco se oculta en la propia esencia de este proyecto de intervención, porque la biblioteca conquista el espacio público y se convierte en necesario agente de socialización; deja de ser, así, un reducto inaccesible y se transforma en un instrumento de difusión cultural y cívica. Y con ella, el maestro, en su agente dinamizador.

Sin embargo, para el bando de los golpistas, con Romualdo de Toledo en el nuevo Ministerio, y José María Pemán en la Comisión de Cultura y Enseñanza de la Junta Técnica del Estado, censor eficaz y uno de los artífices de la depuración perpetrada contra el cuerpo docente, los asuntos de la cultura, las bibliotecas y la difusión cultural no eran cuestiones prioritarias en la nueva agenda política. Sí lo era, en cambio el manual

\footnotetext{
${ }^{26}$ Sobre la naturaleza de esta editorial nos basta la referencia que aporta J. L. Ruiz Sánchez: "El Apostolado de la Prensa no es una Casa Editorial, [...] es un centro de sociedad de propaganda católica y social. Un púlpito permanente que predica sin cesar aun a los que jamás van a la iglesia. No busca, pues, más que el bien moral de las almas, ni tiene más interés que el difundir la luz de la verdad y el manjar de la piedad sólida". (RUíZ SÁNCHEZ, 2002, p. 111).

27 En 1902, convencido de la importancia de la educación, funda las Escuelas del Sagrado Corazón para niños y niñas pobres, aplicando los métodos de la Escuela Nueva contextualizados para aquella población, al estilo de las Escuelas del Ave María, del Padre Manjón.
} 
escolar, instrumento ideológico de propaganda y difusión de consignas políticas y dogmas religiosos, como hemos tenido ocasión de comprobar. El manual escolar como instrumento aleccionador, cuyo contenido debía responder "únicamente, a los sanos principios de la Religión y de la Moral cristiana, y que exalten con sus ejemplos el patriotismo de la niñez"28. Discursos de dictadores, vidas de santos, relatos heroicos, consignas patrióticas ("factores que directamente contribuyen a la formación espiritual del niño"), son los pilares que establecen los ganadores para sostener el nuevo régimen. Por esta razón, como dice literalmente el texto de la circular sobre libros de texto que difunde el Gobierno Civil de Pontevedra el 12 de septiembre de 1936,

\begin{abstract}
Es de importancia suma que los libros que se ponen al alcance de los niños, tengan aquella orientación que requieren las conveniencias espirituales del alumno y reclaman a un mismo tiempo el bien de España y las necesidades del momento, que el movimiento militar salvador de la Patria está imprimiendo en todos sus preceptos. Y no puede admitirse sobre todo, en manera alguna, que los libros escolares contengan nada que se oponga a esta orientación y acusen, no ya antirreligión o antipatriotismo, sino ni siquiera tibieza en la expresión de estos grandes sentimientos. ${ }^{29}$
\end{abstract}

De este modo, fue necesario hacer desaparecer aquellas bibliotecas compuestas por obras representativas de la literatura española e internacional, de estilos e ideología variada tendentes a ensanchar horizontes y acercar culturas en el marco de un nuevo tiempo republicano. Debían ser eliminadas, porque poseían libros "verdaderamente nocivos en ambos sentidos y propios para perturbar y envenenar el alma de los niños". 30

Es significativo, por último, el papel de los maestros en la articulación de las bibliotecas populares, puesto que, como nos recuerda Martínez Rus (2013), casi todas, escolares o municipales, fueron confiadas a los maestros de las respectivas localidades, que se convirtieron en sus principales valedores, pues la falta de recursos impidió la colocación de bibliotecarios profesionales. El papel de los maestros republicanos y el de los maestros en tiempos de la República. Siguiendo el sarcasmo de Jaime Solá citado en páginas anteriores, los primeros vilmente "sustituidos"; y los segundos, sobrevivientes en tiempos de dictadura luego de ser "llamados a la cordura". Eficaces instrumentos, todos ellos, para la defensa de una u otra causa.

\title{
Referencias
}

ALONSO MONTERO, Xesús; VILLAR, Miro. Guerra Civil e literatura galega. Textos e documentos para unas xornadas de estudo e debate. Santiago: Consello da Cultura Galega, 1999.

ASENSI DÍAZ, Jesús. Memorias de un maestro. Memoria de una escuela. Tendencias Pedagógicas, Madrid, Universidad Autónoma, n. 14, p. 33-55, 2009.

BORQUE LÓPEZ, Leonardo. Bibliotecas, archivos y guerra civil en Asturias. Gijón: Ediciones Trea, 1997.

CID FERNÁNDEZ, Xosé Manuel. Educación e Ideoloxía en Ourense na llạ República.

28 Orden n 13 de 4 de septiembre de 1936, de "Incautación y destrucción" emitida por la Junta de Defensa Nacional desde Burgos (BO de la JDNE, 8 de septiembre de 1936).

29 "Circular del Gobierno Civil de la Provincia sobre los libros de texto". El Noticiero Gallego (Revista de Primera Enseñanza), no 2071, de 18 de septiembre de 1936.

$30 \mathrm{lbidem}$. 
Santiago: Andavira, 2010.

COSTA RICO, Antón. Historia da Educación e da Cultura en Galicia. Vigo: Edicións Xerais de Galicia, 2004.

DIEGO PÉREZ, Carmen. Intervención del primer Ministerio de Educación Nacional del franquismo sobre los libros escolares. Revista Complutense de Educación, Madrid, Universidad Complutense, n. 2, p. 53-72, 1999.

. Un caso paradigmático de represión cultural: depuración de bibliotecas escolares en la provincia de Palencia durante la guerra civil española. Las bibliotecas del patronato de misiones pedagógicas en la provincia de Palencia: dotación y depuración de sus fondos ( $2^{\mathrm{a}}$ parte). Disponible en:

$<$ http://www.represura.es/represura_7_febrero_2011_sumario.html>. Aceso en: 7 set. 2014.

DIEGO PÉREZ, Carmen; GONZÁLEZ FERNÁNDEZ, Montserrat. Gestación, dotación y expurgo de las bibliotecas escolares en España: 1869-1939. In: Museos Pedagógicos. La memoria recuperada. Huesca: Gobierno de Aragón. Departamento de Educación, Cultura y Deporte / Museo Pedagógico de Aragón, 2008, p. 283-308.

EL NOTICIERO GALLEGO. Revista de Primera Enseñanza, ㄲo 2071, de 18 de setembro de 1936.

FAUS SEVILLA, Pilar. La lectura pública en España y el Plan de Bibliotecas de María Moliner. Madrid: Anabad, 1990.

GALLEGO, Ferrán. Ramiro Ledesma Ramos y el fascismo español. Madrid: Síntesis, 2005.

GURRIARÁN, Ricardo. Ciencia e conciencia na Universidade de Santiago (1900-1940). Santiago: Universidade de Santiago, 2006.

LEDESMA RAMOS, Ramiro. Discurso a las Juventudes de España. Madrid: Ediciones de La Conquista del Estado, 1935.

LÓPEZ COBO, Azucena. Por caminos de piedra, charcos y olvido: repertorios de la cultura universal: las Misiones Pedagógicas de la II República española. Pandora: revue d'etudes hispaniques, Vincennes -Saint Denis, Université Paris VIII, n. 7, p. 83-98, 2007.

LOZANO SEIJAS, Claudio. Historia de la Educación en España IV. La educación durante la segunda república y la guerra civil (1931-1939). Madrid: Centro de Publicaciones. Secretaría General Técnica del Ministerio de Educación y Ciencia, 1991.

MARTÍN-SÁNCHEZ JULIÁ, Fernando. Origen, ideas e historia de la Institución Libre de Enseñanza. In: Una poderosa Junta secreta. La Institución Libre de Enseñanza, San Sebastián: Editorial Española, 1940.

MARTÍNEZ RUS, Ana. La política del libro durante la Segunda República. Socialización de la lectura. Gijón: Ediciones Trea, 2003.

La República de los libros. Disponible en: <http://hispanianova.rediris.es.>. Aceso en: 23 oct. 2014.

MORENTE VALERO, Francisco. La escuela y el Estado nuevo: la depuración del magisterio nacional (1936-1943). Valladolid: Ámbito, 1997.

OTERO URTAZA, Uxío. As misións Pedagóxicas na España rural republicana. Eduga Revista Galega do Ensino, Santiago, Xunta de Galicia, № 51, p. 52-56, 2007.

. El guiñol y los romances en las Misiones Pedagógicas. In: FLORES PAZOS,

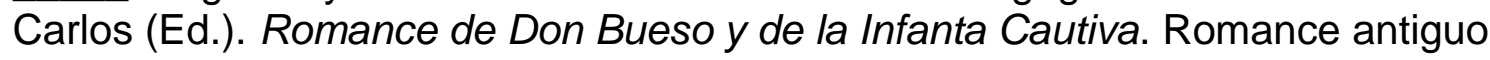


escenificado por Rafael Alberti. Cádiz: Diputación Provincial de Cádiz, 2006, p. 39-55.

. Las Misiones Pedagógicas: una experiencia de educación popular. Sada (A Coruña): Ediciós do Castro, 1982.

. Manuel Bartolomé Cossío, presidente del Patronato de Misiones Pedagógicas. In: Misiones Pedagógicas 1931-1936. Madrid: Sociedad Estatal de Conmemoraciones Culturales/Publicaciones de la Residencia de Estudiantes, 2006, p. 231-239.

Presentación. In: Misiones Pedagógicas 1931-1936. Madrid: Sociedad Estatal de Conmemoraciones Culturales/Publicaciones de la Residencia de Estudiantes, 2006, p. 2531.

. Rafael Dieste y las Misiones Pedagógicas. Documentos A, Madrid: Editorial Anthropos, n. 1, 1991, p. 142-144.

PATRONATO DE MISIONES PEDAGÓGICAS. Memoria 1931-1933. Madrid: S. Aguirre Impresor, 1934. Impresor, s.a.

Reglas para la concesión y funcionamiento de las bibliotecas. Madrid: S. Aguirre

PORTO UCHA, Ángel. La Institución Libre de Enseñanza y la renovación pedagógica en Galicia. Sada-A Coruña: Ediciós do Castro, 2005.

. Mestres e mestras pontevedreses depurados polo franquismo. Primeiras accións represivas e estudo por concellos no sur da provincia de Pontevedra (1936-1942). Ponteareas: Edicións Alén Miño, 2008.

PUELLES BENÍTEZ, Manuel de. La política del libro escolar en España. Del franquismo a la restauración democrática. In: ESCOLANO BENITO, Agustín (Dir.). Historia ilustrada del libro escolar en España. De la posguerra a la reforma educativa. Madrid: Fundación Germán Sánchez Ruipérez, 1998, p. 49-71.

REDONDO ABAL, Francisco Xabier. Bibliotecarios e bibliotecarias "infames". A depuración franquista do corpo bibliotecario republicano. O caso galego. Santiago de Compostela> Edicións Laiovento, 2014.

RUÍZ SÁNCHEZ, José Leonardo. Prensa y propaganda católica (1832-1965). Sevilla: Universidad de Sevilla, 2002.

SOUTO BLANCO Maㅡ Jesús. La represión franquista en la provincia de Lugo (1936-1940). Sada-A Coruña: Ediciós do Castro, 1998.

TOLEDO, Romualdo de. Más organismos creados por la República. In: Una poderosa junta secreta. La Institución Libre de Enseñanza. San Sebastián: Editorial Española, 1940, p. 213-217.

VALLS, Rafael. La historiografía escolar española en la época contemporánea. De la manualística a la historia de la disciplina escolar. In: Historiografía escolar española.

Siglos XIX-XX. Madrid: UNED, 2007.

XOSÉ M. MALHEIRO GUTIÉRREZ (Moxico, Angola, 1961) es Doctor en Filosofía y Ciencias de la Educación por la Universidad de Santiago de Compostela y Profesor en el Dpto. de Pedagoxía e Didáctica de la Facultad de Ciencias de la Educación de la Universidade da Coruña. Anteriormente lo fue en la de Vigo (2001-2002) y la de Santiago (2003-2008). Ha publicado diferentes trabajos sobre la intervención educativa de la emigración gallega a América y ha ganado, además, varios premios relacionados con la investigación histórico- 
educativa. Es miembro de los grupos de investigación Esculca (USC) y Política educativa, Historia e Sociedade (UDC). Pertenece a la SEDHE y al consejo de redacción de su revista científica y órgano de expresión de la Sociedad, Historia y Memoria de la Educación. Es miembro del movimiento de renovación pedagógica Nova Escola Galega. Investiga sobre los procesos migratorios y sus implicaciones en la escuela; el contenido de los manuales escolares; y el empleo de la fotografía y el cine como recursos para el estudio de la memoria escolar.

Dirección: Paseo de Portugal, 113 - Pasaxe-Camposancos - 36788 - A Guarda/Pontevedra España.

E-mail: jose.malheirog@udc.gal

Recebido em 02 de agosto de 2016.

Aceito em 03 de setembro de 2016. 